\title{
Dynamical Downscaling of Future Hydrographic Changes over the Northwest Atlantic Ocean 0
}

\author{
SANG-IK SHIN \\ CIRES, University of Colorado Boulder, and Physical Science Division, NOAA/Earth System Research Laboratory, \\ Boulder, Colorado \\ Michael A. AleXANDER \\ Physical Science Division, NOAA/Earth System Research Laboratory, Boulder, Colorado
}

(Manuscript received 5 July 2019, in final form 7 November 2019)

\begin{abstract}
Projected climate changes along the U.S. East and Gulf Coasts were examined using the eddy-resolving Regional Ocean Modeling System (ROMS). First, a control (CTRL) ROMS simulation was performed using boundary conditions derived from observations. Then climate change signals, obtained as mean seasonal cycle differences between the recent past (1976-2005) and future (2070-99) periods in a coupled global climate model under the RCP8.5 greenhouse gas trajectory, were added to the initial and boundary conditions of the CTRL in a second (RCP85) ROMS simulation. The differences between the RCP85 and CTRL simulations were used to investigate the regional effects of climate change. Relative to the coarse-resolution coupled climate model, the downscaled projection shows that SST changes become more pronounced near the U.S. East Coast, and the Gulf Stream is further reduced in speed and shifted southward. Moreover, the downscaled projection shows enhanced warming of ocean bottom temperatures along the U.S. East and Gulf Coasts, particularly in the Gulf of Maine and the Gulf of Saint Lawrence. The enhanced warming was related to an improved representation of the ocean circulation, including topographically trapped coastal ocean currents and slope water intrusion through the Northeast Channel into the Gulf of Maine. In response to increased radiative forcing, much warmer than present-day Labrador Subarctic Slope Waters entered the Gulf of Maine through the Northeast Channel, warming the deeper portions of the gulf by more than $4^{\circ} \mathrm{C}$.
\end{abstract}

\section{Introduction}

Projections of future ocean conditions are often requested for long-term planning and management of marine resources. These projections require sustained observations of the system as well as a modeling framework that represents the relevant ocean processes and feedbacks with other systems (e.g., atmosphere, ice, land, biogeochemistry, etc.) to resolve the mechanisms important to variability of the system. In this regard, projections from simulations participating in phase 5 of the Coupled Model Intercomparison Project (CMIP5; Taylor et al. 2012) provide physically

\footnotetext{
Supplemental information related to this paper is available at the Journals Online website: https://doi.org/10.1175/JCLI-D-190483.s1.
}

Corresponding author: Sang-Ik Shin, sangik.shin@noaa.gov consistent estimates of climate change over the northwest Atlantic, since those simulations include state-ofthe-art ocean processes and feedbacks among subsystems. However, CMIP5 models have several intrinsic shortcomings, including coarse horizontal resolution, on the order of $1^{\circ}$ in the midlatitude oceans, and a limited number of vertical ocean layers. Moreover, errors in coupled climate models are not uniformly distributed over the globe; for example, sea surface temperature (SST) errors are generally largest along the continental margins (e.g., Fig. 3 in He and Soden 2016).

How can we improve climate projections for coastal oceans? One approach is to use a high-resolution coupled climate model. Climate models with very high resolution $(\sim 10 \mathrm{~km})$ in the ocean component used by Small et al. (2014), Griffies et al. (2015), and Saba et al. (2016) were successful in reproducing many aspects of the ocean state and in reducing biases in the coastal oceans, including the northeast U.S. coast. However, the current-generation 
high-resolution coupled climate models still have substantial mean biases. For example, the cold SST bias in the central North Atlantic remains and can exceed $5^{\circ} \mathrm{C}$ in some high-resolution models (e.g., Fig. 2 in Saba et al. 2016).

Theoretical models can also be used to downscale the future coastal ocean climate. Recently, Minobe et al. (2017) developed a theoretical model for sea level variability along the western boundary using interior ocean sea level information and applied it to assess the future sea level changes between the end of the twentieth and twenty-first centuries by using the CMIP5 interior ocean information. The model successfully captures the future sea level rise along the western North Atlantic, qualitatively consistent with the CMIP5 multimodel mean. However, such theoretical models cannot produce all necessary coastal ocean fields for long-term planning and management of marine resources, such as temperature, salinity, and ocean circulation.

Meanwhile, previous studies have shown that uncoupled regional ocean models, employing a high-resolution grid in both horizontal and vertical directions, improve many aspects of ocean processes along continental margins, including topographically trapped coastal currents, eddies, tidal mixing, river plumes, etc. Regional models have been especially useful in simulating ocean processes along the U.S. East Coast and Gulf of Mexico (e.g., Curchitser et al. 2005; Kang and Curchitser 2013, 2015) and for shelf and bays in the Gulf of Mexico and Atlantic seaboard (Liu et al. 2012; Alexander et al. 2020), due to their complex coastlines, highly variable bathymetry, and proximity to strong coastal currents. Regional ocean models can be used to investigate climate change by forcing them with bias-adjusted future projections from global models. This has generally been done using the "delta method," where long-term mean differences in oceanic and atmospheric fields between the recent past and future periods were derived from coupled climate models, and then added to the observed present-day conditions. By design, this approach only considers the effects of the long-term climate change (forced) signal and neglects the somewhat uncertain future projections at higher frequencies, such as changes in storm tracks and interannual climate variability.

Differences between low-resolution coupled and high-resolution regional models are illustrated in Fig. 1, which shows the wintertime temperature and circulation patterns along the northeast U.S. shelf (see Fig. S1 in the online supplemental material for the summertime). The fields are obtained from the Geophysical Fluid Dynamics Laboratory (GFDL) Earth System
Model that includes ocean biogeochemistry, the GFDLESM2M (Dunne et al. 2012), and 7-km Regional Ocean Modeling System (ROMS) (see section 2a for details). For example, at the surface ROMS exhibits a southeastward directed coastal current along Nova Scotia that flows counterclockwise around the Gulf of Maine (see the schematics in Fig. 2). These currents are weak or absent in the climate model. As observed, cold SSTs $\left(<7^{\circ} \mathrm{C}\right)$ extend over the entire Gulf of Maine in ROMS, but they occur only in the very northern part of the Gulf in GFDL-ESM2M. At 155-m depth, ROMS clearly shows the intrusion of slope waters into the Gulf of Maine through the Northeast Channel as in observations (e.g., Brooks 1987). The slope waters are a deep-water mass, consisting of Labrador Slope Water and Warm Slope Water, and recognized as the major source of dissolved inorganic nutrients to the Gulf (e.g., Townsend et al. 2014; Townsend et al. 2015). The Gulf of Maine, including the Northeast Channel, is not resolved in GFDL-ESM2M.

A more detailed examination of changes in the Gulf of Maine is warranted given that it has very complex bathymetry and that it is near the confluence of the cold Labrador Current and warm Gulf Stream (see Fig. 2). It has also experienced very strong warming over the recent past (e.g., Pershing et al. 2015) that is projected to continue into the future (e.g., Saba et al. 2016). The rapidly warming temperatures and accompanying changes in currents and biogeochemistry will strongly impact marine ecosystems along the northeast U.S. coast, (e.g., Hoegh-Guldberg and Bruno 2010), with adverse effects on species such as Atlantic cod (e.g., Pershing et al. 2015) and lobster (Le Bris et al. 2018).

In this study, we are interested in downscaling the future coastal ocean climate under the representative concentration pathway (RCP) 8.5 scenario. Here, we extend the previous one-way nested regional ocean model approach by retaining the "mean seasonal cycle" of the delta forcing fields. Recently, Alexander et al. (2020) provided a general survey of such downscaled future coastal ocean climate under the RCP8.5 scenario using three CMIP5 participating coupled climate models including the GFDL-ESM2M, and here we performed a detailed analysis of the one driven by the GFDLESM2M. The choice of GFDL-ESM2M is for the qualitative comparisons with the recent study of Saba et al. (2016), where a high-resolution GFDL coupled climate model was used to assess the future coastal ocean climate. The sensitivity of downscaled future climate to the choice of AR5 coupled climate model was given in Alexander et al. (2020). This paper is organized as follows: a summary of the models and methods are given in section 2; the results of downscaled ocean 
$5 \mathrm{~m}$
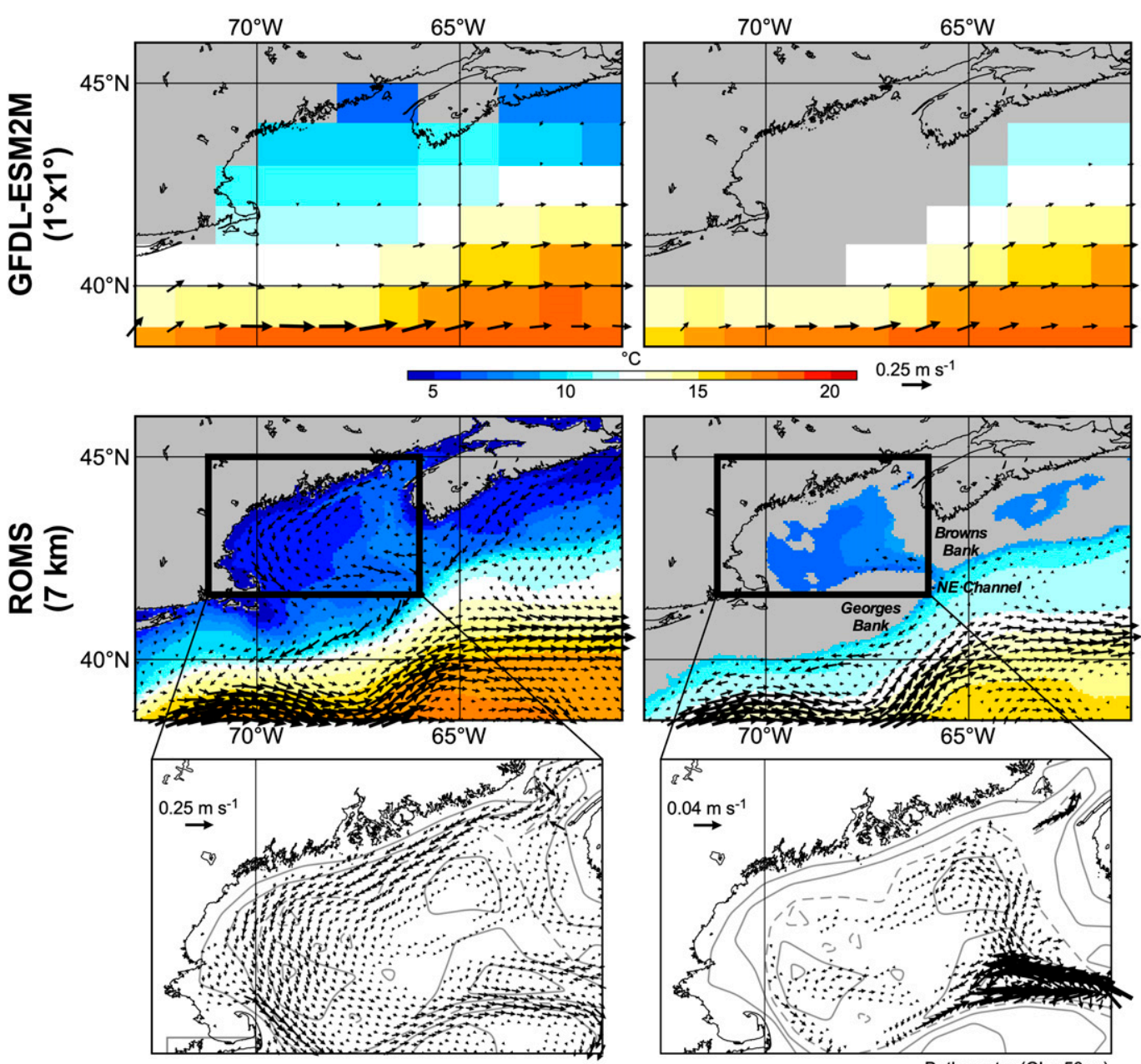

$155 \mathrm{~m}$

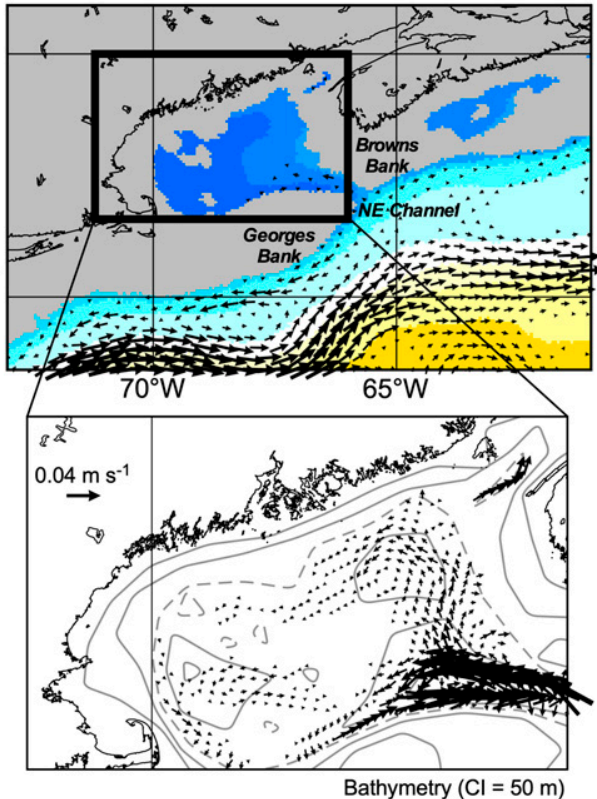

FIG. 1. (left) Wintertime (DJF) temperature (shading) and currents (arrows) at 5-m depth over the Gulf of Maine during 1976-2005 derived from (top) the coarse-resolution GFDL ESM2M and (bottom) the fine-resolution ROMS. (right) As in left, but for the patterns at 155-m depth.

climate changes over the entire model domain are summarized in section 3; a detailed assessment of the changes in the Gulf of Maine are given in section 4; and a summary and concluding remarks follow in section 5 .

\section{Models and methods}

We first used ROMS to perform a control simulation (hereafter CTRL) of the recent past along the U.S. East and Gulf Coasts. The large-scale projected changes (i.e., deltas) were obtained from the GFDL-ESM2M simulations of historical and future periods. Then, these delta fields were added to the initial and boundary conditions of the CTRL in a second ROMS simulation (hereafter RCP85). A brief description of ROMS, the
GFDL-ESM2M simulations used, and delta method are given below.

\section{a. Regional ocean model}

Our study uses ROMS (Shchepetkin and McWilliams 2005), a sigma-coordinate primitive equation ocean model, with the same domain and physics as in Kang and Curchitser (2013). The model domain covers the northwest Atlantic Ocean and Gulf of Mexico (NWA; see Fig. 2) with a horizontal resolution of $7 \mathrm{~km}$ and 40 vertical terrainfollowing levels. For the CTRL simulation, initial and ocean lateral boundary conditions (BCs) were derived from the Simple Ocean Data Assimilation (SODA; Carton and Giese 2008) version 2.1.6, air-sea fluxes were calculated from the surface atmospheric forcing fields extracted from the Coordinated Ocean-ice Reference 


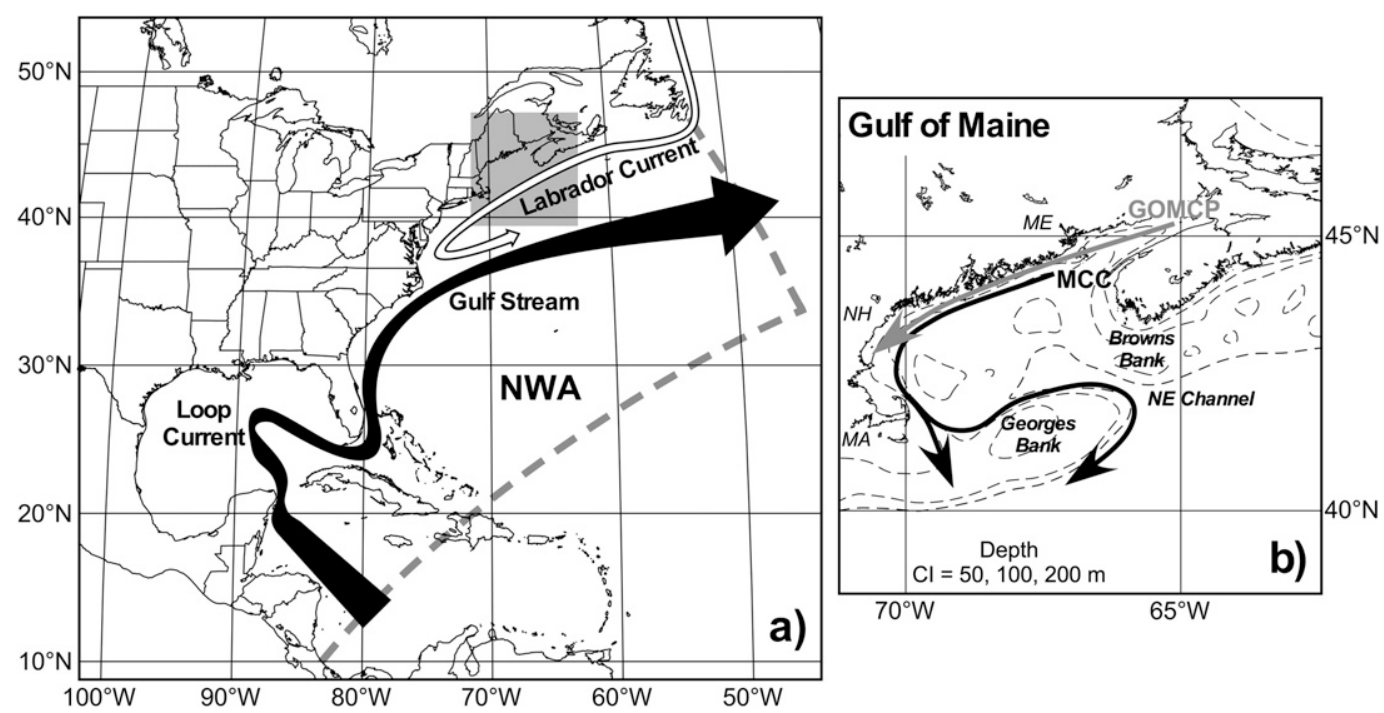

FIG. 2. (a) Schematics of major current systems in our downscaling domain covering the northwest Atlantic Ocean and Gulf of Mexico (NWA). Thick gray dashed line indicates the position of open boundaries of the NWA region. (b) Major current systems in Gulf of Maine [denoted as gray shading in (a) shown with solid arrows: black $=$ Maine Coastal Current $($ MCC) ; gray $=$ Gulf of Maine Coastal Plume (GMCP)]. Abbreviations used: $\mathrm{MA}=$ Massachusetts; $\mathrm{NH}=$ New Hampshire; $\mathrm{ME}=$ Maine.

Experiments (CORE) version 2 dataset (Large and Yeager 2009), and river discharge was implemented as a freshwater flux using the global river flow and continental discharges database (Dai et al. 2009). A more detailed description of the model physics is given in Kang and Curchitser (2013).

The CTRL was very successful in simulating many aspects of present-day climate conditions over the NWA as discussed in Kang and Curchitser (2013). In Fig. 3, we compared the climatological annual mean surface currents derived from the CTRL (during the years 1976-2005) to the satellite-tracked surface drifting buoy (during 1979-2015; Lumpkin and Johnson 2013) and the SODA dataset (during 1976-2005). Despite the difference in time averaging periods and the uncertainties of model and Lagrangian drifter data, CTRL captures the observed circulation patterns in the NWA, including the observed clockwise shelf circulation in the Gulf of Mexico. Such coastal circulation was not resolved in the relatively low-resolution SODA reanalysis. The SODA reanalysis has a horizontal resolution of about $0.25^{\circ}$ latitude $\times 0.4^{\circ}$ longitude with 40 vertical levels (note that the SODA had less than 15 vertical levels at the coastal ocean where depth is shallower than $200 \mathrm{~m}$ ). The Gulf Stream in CTRL, however, shows an exaggerated split into two branches over the regions between $65^{\circ}$ and $55^{\circ} \mathrm{W}$, although the drifter also indicates some hints of this split. We also assessed the annual average of SSH derived from AVISO data (http://marine.copernicus.eu) and the surface currents derived from the OSCAR
(Bonjean and Lagerloef 2002) dataset. Both datasets, however, do not show the split of Gulf Stream (figure not shown).

\section{b. Coupled global climate model simulations}

The coupled climate model simulations used in this study are the historical (1976-2005) and the RCP8.5 (2070-99) simulations from the GFDL-ESM2M. The atmospheric component, the Atmospheric Model version 2 (AM2; Anderson et al. 2004), has a horizontal resolution of $2^{\circ}$ latitude $\times 2.5^{\circ}$ longitude with 24 vertical levels. The ocean component, MOM4p1 (Griffies et al. 2005), has $\sim 1^{\circ}$ horizontal resolution with 50 vertical levels. The horizontal resolution of the ocean component decreases to $1 / 3^{\circ}$ meridionally at the equator and uses tripolar grid north of $65^{\circ} \mathrm{N}$. A detailed description of model physics is given by Dunne et al. (2012).

The historical run is designed to simulate the recent past (1850-2005) by imposing observed radiative forcing changes due to natural (e.g., volcanoes) and anthropogenic influences. The RCP8.5 scenario, the projection with the greatest increase in greenhouse gasses in CMIP5, starts in 2006 with the level of radiative forcing reaching $8.5 \mathrm{~W} \mathrm{~m}^{-2}$ by 2100 . The atmospheric $\mathrm{CO}_{2}$ rises from 354.14 (average of 1976-2005) to $798.51 \mathrm{ppm}$ (average of 2070-99), although other trace gases contribute to the radiative forcing. The increase in radiative forcing under the RCP8.5 scenario causes the global surface temperature to rise by $2^{\circ}-5^{\circ} \mathrm{C}$ at the end of twenty-first century relative to the 1986-2005 average depending 
a) ROMS

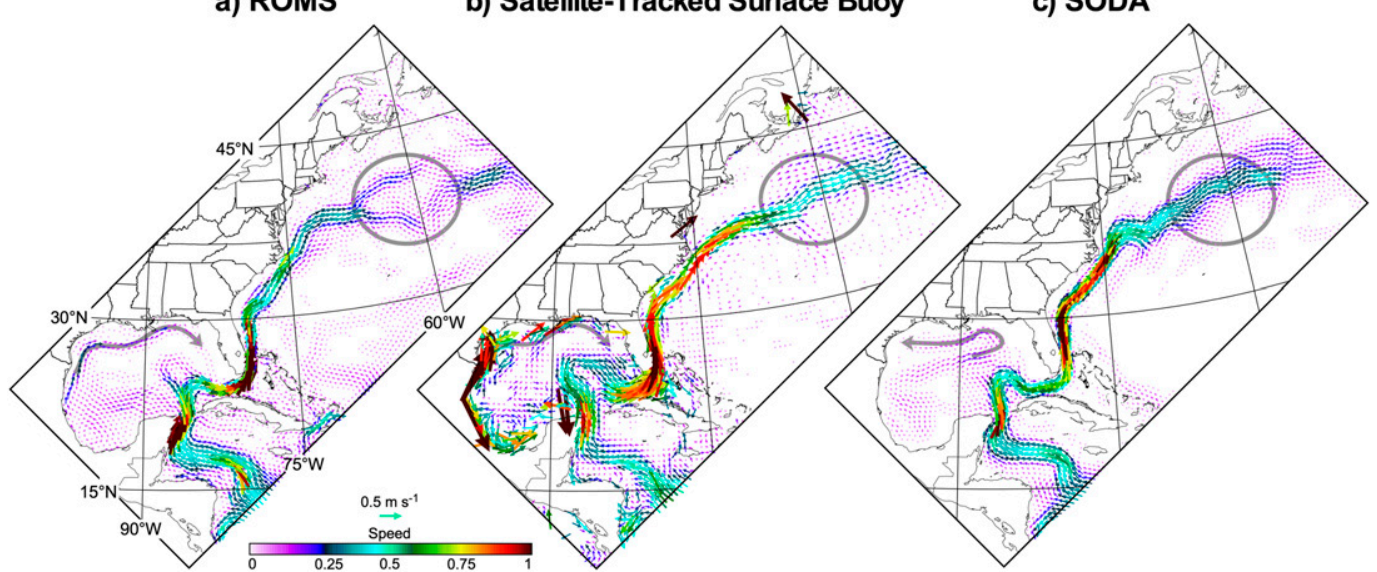

c) SODA

FIG. 3. Maps of annually averaged surface current derived from (a) ROMS CTRL (averaged over during 19762005), (b) satellite-tracked surface buoy dataset (averaged over during January 1979-March 2015; Lumpkin and Johnson 2013), and (c) SODA version 2.1.6 dataset (averaged over during 1976-2005). The colors indicate the speed of surface current. The gray circle and gray line with arrow highlight the exaggerated Gulf Stream split in ROMS and a clockwise coastal circulation over the Gulf of Mexico, respectively.

on which climate model is used (IPCC 2013). In GFDLESM2M, the projected change is about $4.5^{\circ} \mathrm{C}$.

Many previous studies (e.g., Cheng et al. 2013) found that the increase in radiative forcing weakens the Atlantic meridional overturning circulation (AMOC). In the GFDL-ESM2M model simulations, AMOC decreases by about $20 \%\left(\sim 4 \mathrm{~Sv} ; 1 \mathrm{~Sv} \equiv 10^{6} \mathrm{~m}^{3} \mathrm{~s}^{-1}\right)$ from the current climate conditions ( $\sim 20 \mathrm{~Sv}$; figure not shown). The projected regional climate changes over the North Atlantic in GFDL-ESM2M are largely consistent with the climate responses to reduced AMOC. For example, a large ocean surface warming along the northeast U.S. coast that extends into the central North Atlantic and a moderate warming or even a small cooling over the subpolar North Atlantic (Fig. 4a) are consistent with the fingerprint pattern for reduced AMOC (e.g., Cheng et al. 2013; Buckley and Marshall 2016; Caesar et al. 2018). The subtropical North Atlantic is projected to be saltier than in the present day (Fig. 4b), in contrast to the projected fresher subpolar North Atlantic. These surface temperature and salinity responses are also consistent with the projected slowdown of Gulf Stream (Fig. 4c) that decreases meridional oceanic heat and salt transport. The ocean bottom temperatures along

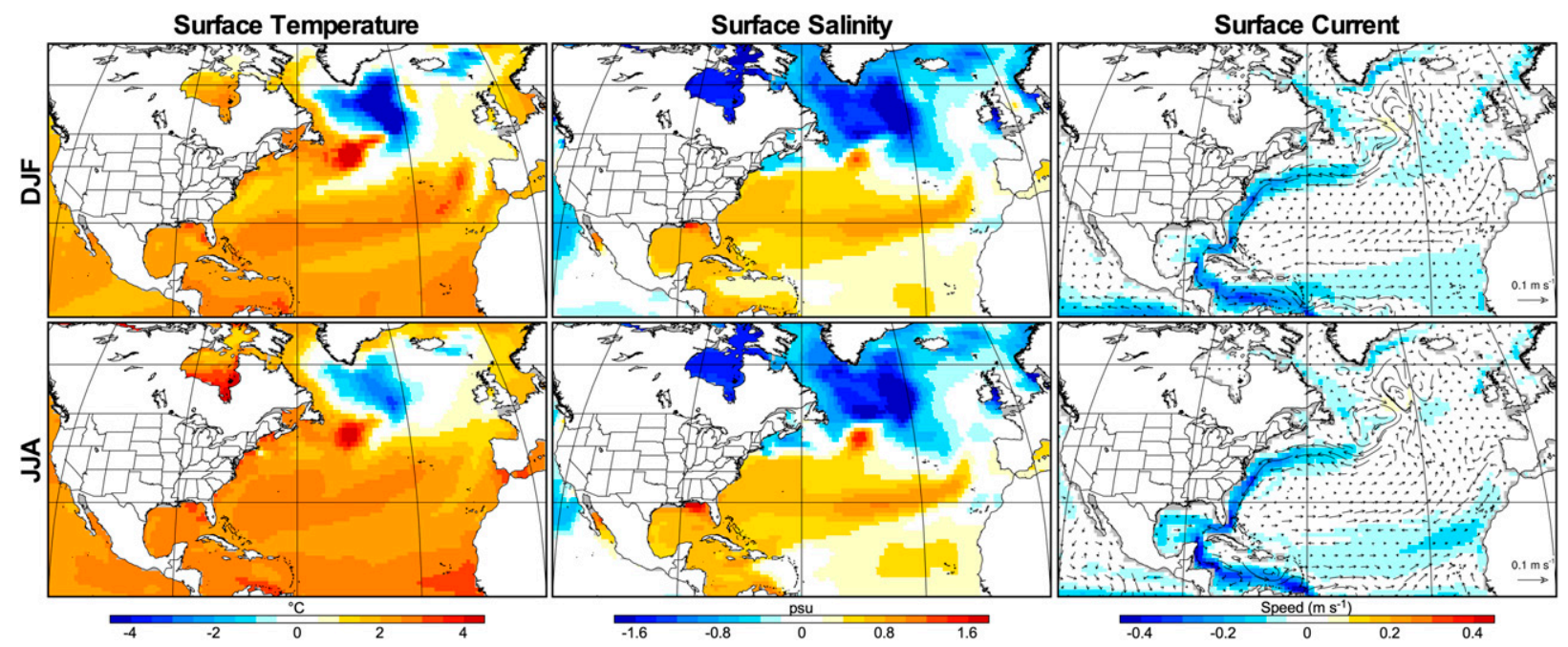

FIG. 4. (top) Maps of DJF GFDL-ESM2M responses of ocean surface (left) temperature, (middle) salinity, and (right) current to $\mathrm{RCP} 8.5$ radiative forcing changes, estimated as the mean differences between two time periods representing future (2070-99) and presentday (1976-2007) climate conditions. (bottom) As in top, but for JJA. 
Bottom Temperature

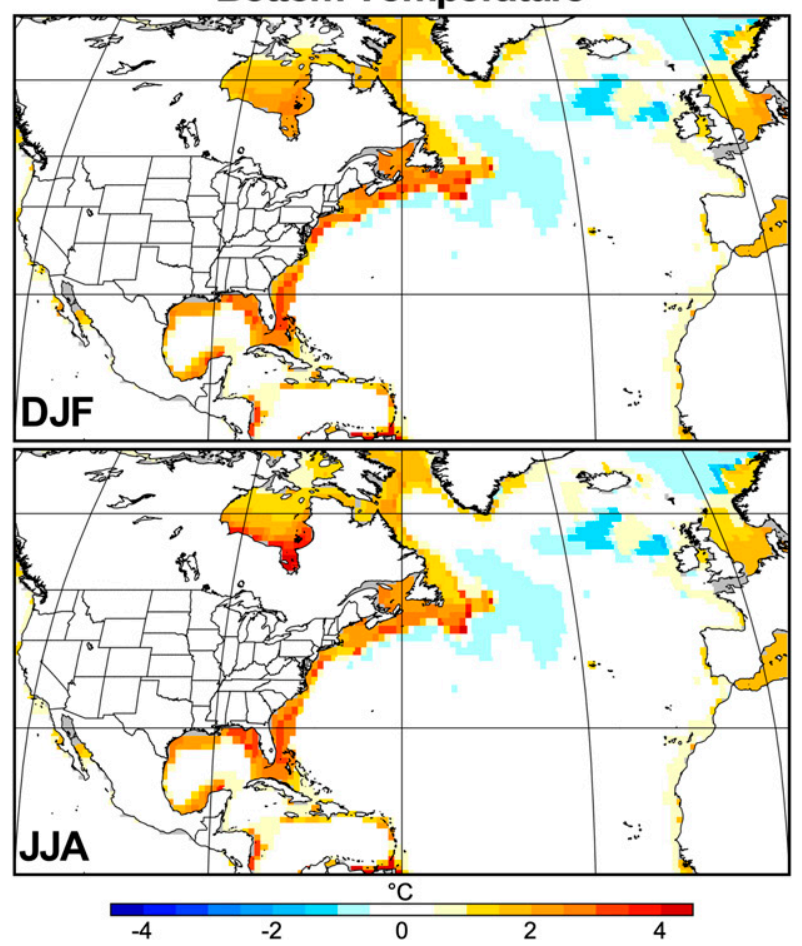

FIG. 5. (top) Maps of DJF GFDL-ESM2M responses of ocean bottom temperature to $\mathrm{RCP} 8.5$ radiative forcing changes, estimated as the mean differences between two time periods representing future (2070-99) and present-day (1976-2007) climate conditions. (bottom) As in top, but for JJA.

the east coast of North America show $2^{\circ}-3^{\circ} \mathrm{C}$ yearround warming (Fig. 5), which is somewhat larger than at the surface (Fig. 4a), suggesting substantial changes in ocean stratification.

\section{c. Seasonally varying delta method}

To produce a high-resolution, bias-adjusted future projection for the NWA region, we dynamically downscale the ocean climate by using the delta method to obtain initial conditions and boundary conditions including the surface atmospheric fluxes. The delta approach has been used previously in many coastal ocean downscaling simulations (e.g., Auad et al. 2006; Liu et al. 2012; van Hooidonk et al. 2015). In those studies, the long-term (typically 10-30yr) annual mean differences in BCs and surface atmospheric forcings between the recent past and future periods were derived from coupled climate models, and then added to the observed present-day conditions. This method does remove the mean bias for the present-day climate of the coupled climate models, but also retains high-frequency spatiotemporal variability of the forcings (i.e., the day-to-day variability and finescale spatial variability of the present-day climate). The delta method, however, neglects the changes in interannual climate variability due to an increase in greenhouse gases.

Here we extended the delta approach by retaining its seasonal cycle, given that climate change signals often show a strong seasonal dependence (Partanen et al. 2017; also see our Fig. 7). The detailed procedure of estimating the seasonally varying delta is as follows:

1) The monthly mean GFDL ESM2M simulated surface atmospheric (Table 1), oceanic (sea surface height, three-dimensional temperature, salinity, and currents), and river runoff fields for $30-\mathrm{yr}$ periods representing the present-day (1976-2005) and future (2070-99; RCP8.5) periods were obtained from the NOAA GFDL CMIP5 repository.

2) The differences of the mean seasonal cycles between two periods were computed to form the seasonally varying deltas as monthly averages.

3) The monthly deltas were bilinearly interpolated both in space and time, and added to the SODA version 2.1.6 (pentad in time and $0.5^{\circ}$ latitude $\times 0.5^{\circ}$ longitude $^{1}$ with 40 vertical levels), CORE version 2 (6-hourly in time and about $1.89^{\circ}$ in latitude and longitude), and Dai et al.'s (2009) global river flow (monthly in time and $1^{\circ}$ in latitude and longitude) historical data (1958-2005) to form a bias-corrected future projection (2052-99).

4) Then, the bias-corrected future atmospheric, oceanic, and river runoff fields were interpolated to the ROMS grid by using the Pyroms package to provide the boundary and initial conditions for the NWA.

Selected maps of the GFDL-ESM2M oceanic changes (deltas) are already shown in Figs. 4 and 5 and discussed in section $2 b$. The maps of deltas for surface atmospheric forcings and river runoff over the North Atlantic during December-February (DJF) and June-August (JJA) are shown in Fig. 6. The changes in surface atmospheric forcings, by design, represent the projected future climate responses to increasing greenhouse gases. For example, surface air temperature over the entire subtropical North Atlantic warms about $2^{\circ}-3^{\circ} \mathrm{C}$ (Fig. 6a). The greenhouse effects contribute to the subtropical warming via increasing surface specific humidity (water vapor; Fig. 6b) and downwelling longwave radiation (Fig. 6d). The seasonal dependence of specific humidity and longwave radiative flux is also evident and

\footnotetext{
${ }^{1}$ Although the SODA experiment employs a horizontal resolution of about $0.25^{\circ}$ latitude $\times 0.4^{\circ}$ longitude with 40 vertical levels, the final product was released in $0.5^{\circ}$ latitude $\times 0.5^{\circ}$ longitude horizontal grid with the same 40 vertical levels.
} 
TABLE 1. Atmospheric forcing variables used to estimate seasonally varying delta. Here we followed the nomenclature of ROMS (CMIP5) standard.

\begin{tabular}{llcc}
\hline \hline ROMS (GFDL-ESM2M) & \multicolumn{1}{c}{ Description } & Units & Resolution \\
\hline pair (psl) & Sea level pressure & $\mathrm{Pa}$ & \\
qair (huss) & Surface specific humidity & $\mathrm{kg} \mathrm{kg}^{-1}$ & \\
tair (tas) & Surface air temperature & $\mathrm{C}$ & \\
uwind (uas) & $10-\mathrm{m} U$-wind component & $\mathrm{m} \mathrm{s}^{-1}$ & $\mathrm{~T} 63$ (CORE2) \\
vwind (vas) & $10-\mathrm{m} V$-wind component & $\mathrm{m} \mathrm{s} \mathrm{m}^{-1}$ & \\
lwrad_down (rlds) & Downwelling LW radiation & $\mathrm{W} \mathrm{m}^{-2}$ & \\
sward (rsds) & Downwelling SW radiation & $\left.\mathrm{kg} \mathrm{m}^{-2} \mathrm{~s}^{-1}\right)$ & Dai and Trenberth discharge grid \\
rain (pr) & Rainfall rate & $\left.\mathrm{kg} \mathrm{m}^{-2} \mathrm{~s}^{-1}\right)$ & River runoff \\
runoff (friver) & R & &
\end{tabular}

responsible for the enhanced warming during summer (Fig. 6a). Positive sea level pressure deltas at midlatitudes along with weak or negative sea level pressure deltas in subtropics reduce the surface westerly winds (Fig. 6e). The decreased subtropical precipitation (Fig. 6f) and freshwater flux through rivers (river runoff; Fig. 6g) along with the general increase of precipitation and river runoff at middle to high latitudes are consistent with the projected expansion of the tropical-subtropical dry zone (Lu et al. 2007; Feng and Fu 2013).

Seasonal differences in the deltas, defined as half of the difference between the maximum and minimum monthly values, are shown in Fig. 7 for surface air temperature, surface specific humidity, and sea level pressure. The observed interannual variations of annual
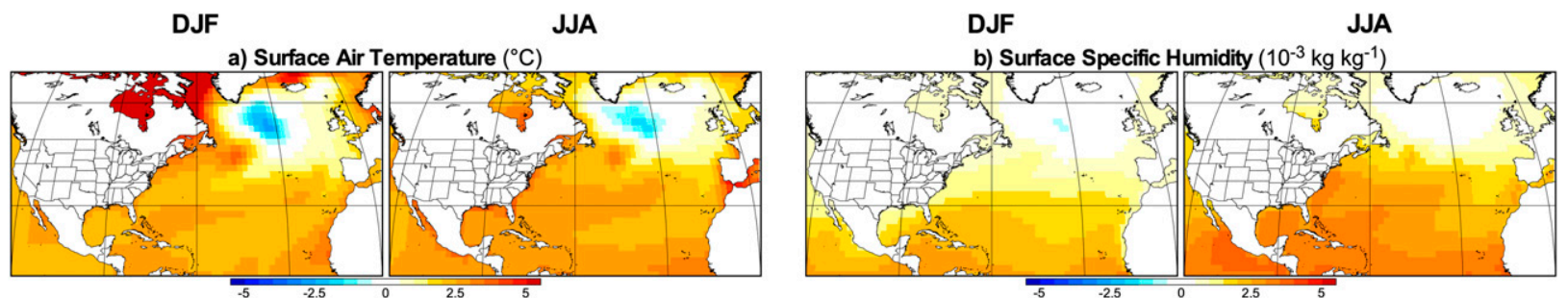

c) Downwelling Solar SW Radiation $\left(\mathrm{W} \mathrm{m}^{-2}\right)$

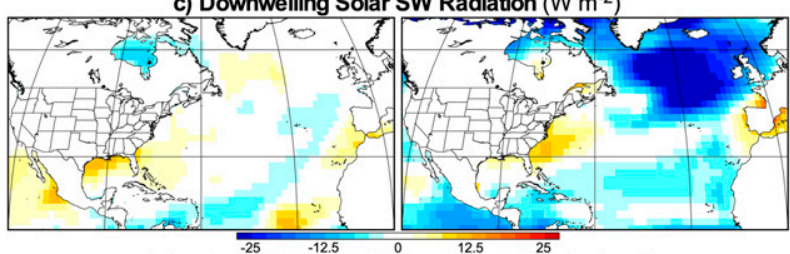

e) Sea Level Pressure ( $\mathrm{Pa})$ and $10 \mathrm{~m}$ Winds $\left(\mathrm{m} \mathrm{s}^{-1}\right)$
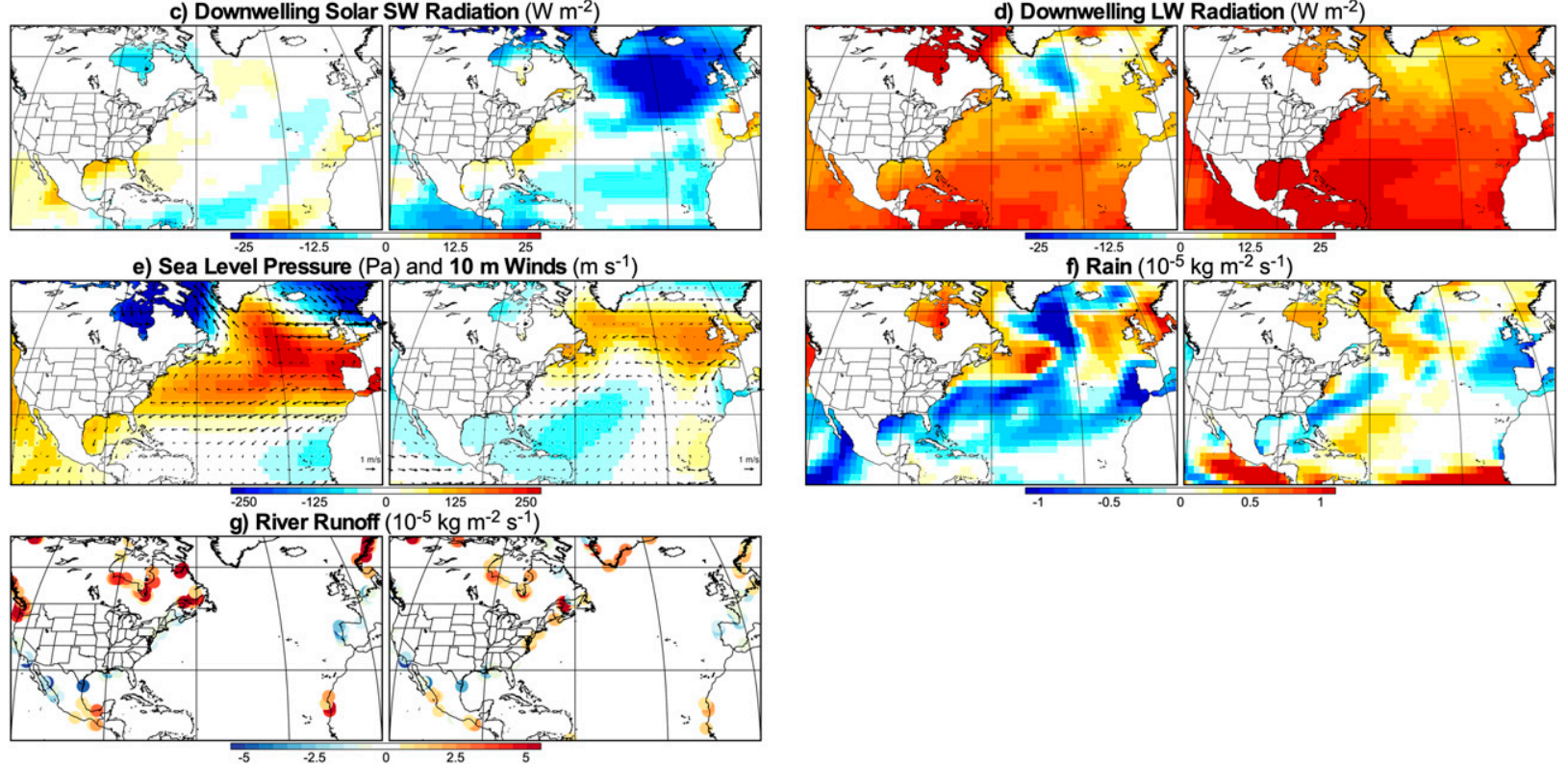

FIG. 6. Maps of DJF and JJA GFDL-ESM2M responses of (a) surface air temperature, (b) surface specific humidity, (c) downwelling solar shortwave radiation, (d) downwelling longwave radiation, (e) sea level pressure and surface $(10 \mathrm{~m})$ winds, (f) rainfall rate, and (g) river runoff to RCP 8.5 radiative forcing changes, estimated as the mean differences between two time periods representing future (2070-99) and present-day (1976-2007) climate conditions. 


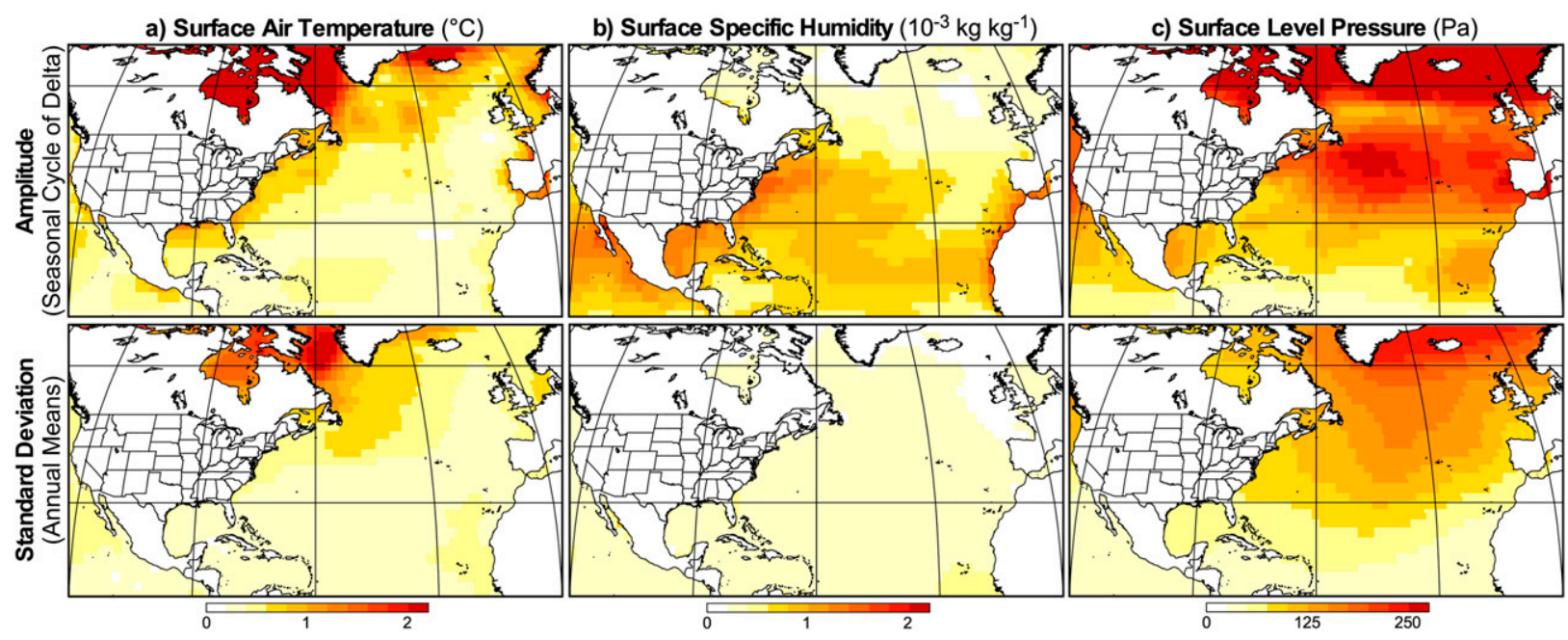

Fig. 7. (top) Maps of the amplitude of seasonal cycle of delta for (a) surface air temperature, (b) surface specific humidity, and (c) sea level pressure, where the amplitude is defined as a half of the difference between the maximum and minimum of monthly delta. (bottom) The standard deviation of annual means of corresponding fields during 1976-2005 derived from the CORE version 2 dataset (Large and Yeager 2009).

means during 1976-2005 are also shown in Fig. 7 for comparison. The seasonal cycle amplitudes of the deltas are comparable to or larger than the interannual variations along the continental margins of the NWA, underlying the importance of using seasonally varying forcing.

\section{d. Downscaling simulations}

We performed a 48-yr CTRL (1958-2005) and RCP85 (equivalent to 2052-99) NWA ROMS simulations, and used the last 30 years of each for analyses, allowing for an 18-yr spinup period. We first assess the downscaled responses, obtained from the difference between the RCP85 and CTRL runs, over the whole NWA domain, and then present a more detailed analysis of the projections in the Gulf of Maine.

\section{Downscaled responses over the NWA domain}

The downscaled RCP85 responses of SST and surface currents are shown with those of the GFDL ESM2M in Fig. 8. For the ease of comparison, the GFDL-ESM2M responses were bilinearly interpolated to the ROMS grid. One consequence of using a high-resolution ocean model is the redistribution of heat, salt, and momentum. In the wind-driven ocean circulation where vorticity input (wind stress) balances vorticity dissipation (lateral diffusion assuming Munk boundary layer; Munk 1950), the thickness of the western boundary layer $\varepsilon_{M}$ is given as $\pi\left(A_{h} / \beta\right)^{1 / 3}$, where $A_{H}$ is the horizontal eddy viscosity and $\beta\left(=\partial_{y} f\right)$ is the variation of Coriolis parameter $(f)$ with latitude. Since ROMS uses 16 times smaller eddy viscosity $\left(25 \mathrm{~m}^{2} \mathrm{~s}^{-1}\right)$ than that of the GFDL-ESM2M ocean model $\left(400 \mathrm{~m}^{2} \mathrm{~s}^{-1}\right)$, the western boundary layer thickness reduces to $\sim 40$ from $\sim 100 \mathrm{~km}$. Therefore, the Gulf Stream is confined to a narrow western boundary layer as shown in Fig. 8. As a consequence, SST changes become more pronounced around the U.S. East Coast in our downscaled runs compared to the coarse GFDLESM2M. Moreover, the maximum speed of Gulf Stream is further reduced in the downscaled runs.

The position shift of Gulf Stream under the RCP8.5 scenario has been assessed in the recent study of Saba et al. (2016), who found that a weakened AMOC in the future leads to a northward shift of the Gulf Stream's separation from the coast. To determine the position change of Gulf Stream in our downscaled runs, we compare the magnitude of horizontal gradient of sea surface height $(\mathrm{SSH}), \sqrt{(\partial \bar{\eta} / \partial x)^{2}+(\partial \bar{\eta} / \partial y)^{2}}$, in the RCP8.5 and CTRL runs in Fig. 9. Many previous studies used the SSH gradient to diagnose the position of the Gulf Stream (e.g., Andres 2016), since the Gulf Stream is better represented as the ocean transport (in unit of Sv) rather than the Ekman-dominated surface current. The ocean is approximately in geostrophic balance at low frequencies, and the SSH gradient is related to the geostrophic velocity as $f \mathbf{k} \times \mathbf{u}_{g}=-g \nabla \eta$ (where $g$ is the acceleration due to gravity and $\mathbf{u}_{g}$ is the geostrophic velocity). Thus, the SSH gradient represents the changes in ocean transport.

In contrast to Saba et al. (2016), our downscaled simulations suggest that the Gulf Stream separation shifts southward under the RCP8.5 scenario. Other studies also highlight the lack of consensus on the direction of this shift in response to a change in AMOC; some modeling 
a) Downscaled

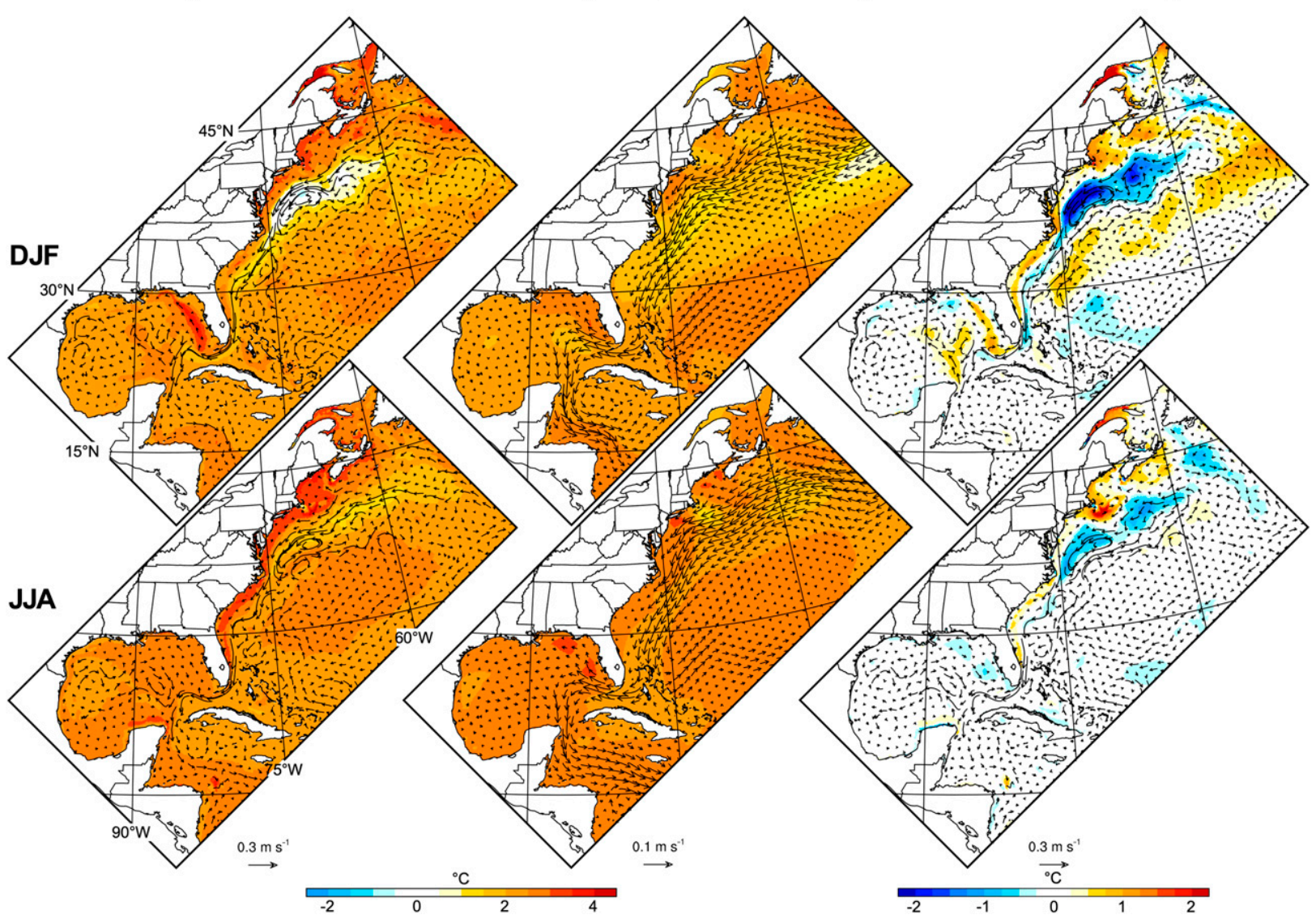

FIG. 8. (top) Maps of projected DJF sea surface temperature (color shadings) and surface current (vectors) responses, derived from (a) ROMS downscaling and (b) GFDL ESM2M simulations. For ease of comparison, the GFDL ESM2M responses were bilinearly interpolated to the ROMS grid. (c) Difference of (a) minus (b). (bottom) As in top, but for the JJA.

studies found a northward shift of the Gulf Stream separation in response to a reduction in AMOC, (e.g., Zhang 2008; Yeager 2015; Saba et al. 2016), while others (e.g., de Coëtlogon et al. 2006; Kwon and Frankignoul 2014) found a southward shift, as in our downscaling simulations.

One may wonder if there is a shift in the mean position of zero wind stress curl, so that the southward shift of Gulf Stream is a direct response to the southward shift in zero wind stress curl. In this regard, we compared the long-term mean wind stress curl in the CTRL (19582005) and delta added RCP85 (2052-99) forcings (see Fig. S2 of the online supplemental material). It shows that there is no apparent shift in mean wind stress curl in our simulations. Thus, the southward shift of Gulf Stream cannot be explained by the shift of wind stress curl. Instead, the southward shift of Gulf Stream may be dynamically related to the reduced AMOC via the joint effect of baroclinicity and relief (JEBAR; Mertz and Wright 1992) (see the appendix).
The warming of bottom temperatures around the U.S. East Coast is enhanced in the downscaled run compared to the coarse-resolution GFDL-ESM2M (Fig. 10). The enhanced warming is pronounced along the continental shelf and shelf break along the Gulf of Mexico and the U.S. East Coast, indicating about a $4^{\circ} \mathrm{C}$ warming, $1^{\circ}-2^{\circ} \mathrm{C}$ more than that projected in the coarse-resolution GFDL-ESM2M. Enhanced warming of about $1^{\circ} \mathrm{C}$ over the Gulf of Maine and the Gulf of Saint Lawrence is also evident.

In addition to inducing long-term hydrographic changes under the RCP8.5 scenario, the increased radiative forcings also impact the occurrence of ocean eddies. The SSH variance $\left(\overline{\eta^{1 / 2}}\right)$, a measure of eddy activity, is shown in Fig. 11 for the CTRL and the RCP85 simulations during DJF and JJA. Here we decomposed the 5-day mean (pentad) SSH data as the sum of lowpass filtered component and anomaly to this low-passed component as $\eta=\bar{\eta}+\eta^{\prime}$. The 24-pentad (equivalent to 120-day) running mean, based on the typical eddy 
a) RCP85

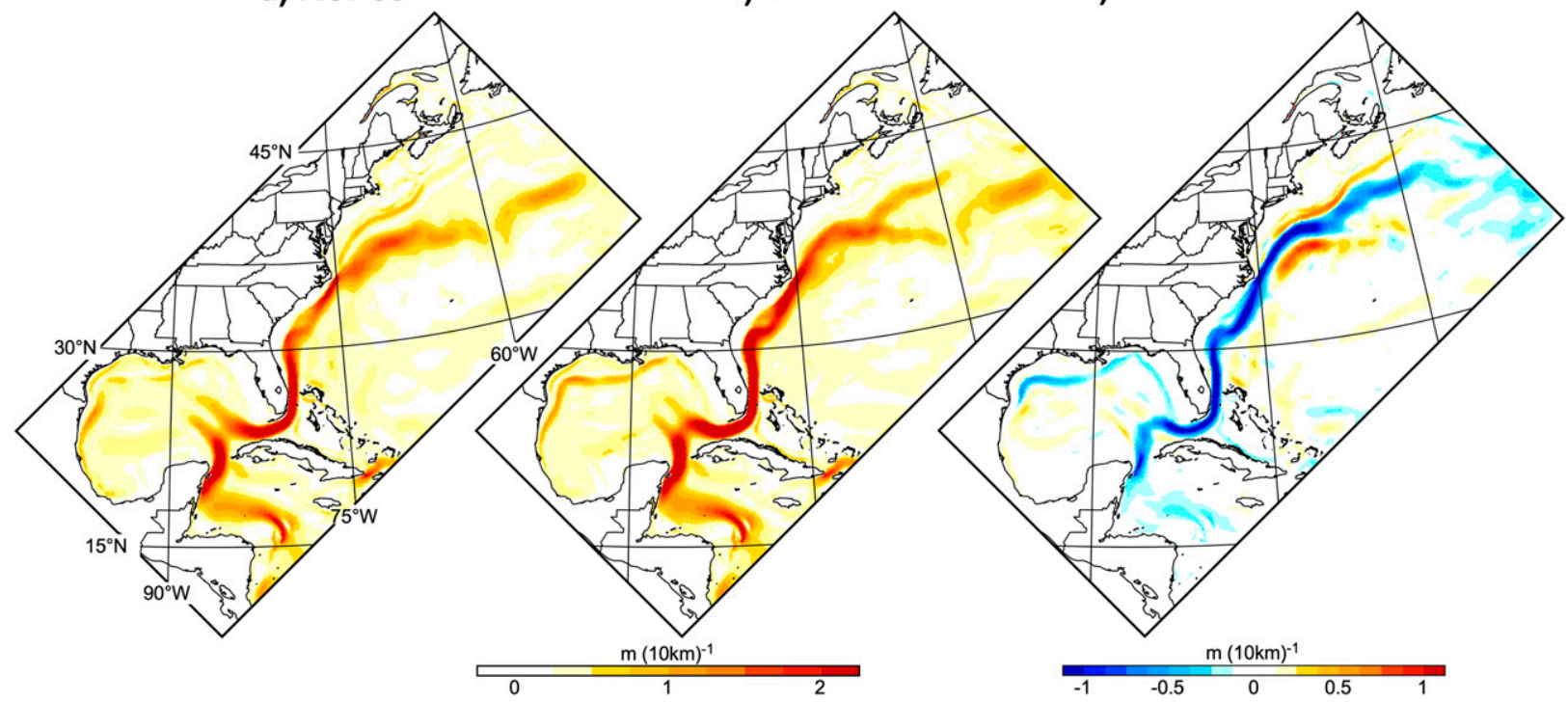

FIG. 9. Maps of horizontal gradient magnitude $\left[\sqrt{(\partial \bar{\eta} / \partial x)^{2}+(\partial \bar{\eta} / \partial y)^{2}}\right]$ of annually averaged sea surface height derived from (a) RCP85 and (b) CTRL simulations, and (c) their difference [(a) minus (b)].

characteristic period over the model domain [50-100 days in the Caribbean (Jouanno et al. 2008) and about 90 days for the long-lived eddies in Gulf Stream (Kang and Curchitser 2013)] forms the low-pass filter.

The CTRL simulation captures the observed seasonal cycle of eddy occurrence in the North Atlantic as well as in the Gulf of Mexico (Fig. 11b). Over the Gulf Stream region, eddy activity dominates during summer, although the spatial pattern of eddy activity is similar in summer and winter (e.g., Zhai et al. 2008). As in observations (e.g., Chang and Oey 2012), the Loop Current appears to shed more eddies during summer than in winter in the Gulf of Mexico.

The changes of eddies in response to increasing radiative forcing are also larger during summertime, though the main response of the Gulf Stream and Loop Current eddies are very different. While eddy activity along the Gulf Stream indicates a southward shift under the RCP8.5 scenario consistent with the shift in Gulf Stream separation, Loop Current eddies in the Gulf of Mexico show an increased occurrence under the RCP8.5 scenario.

The downscaled results are consistent with the previous studies of Liu et al. $(2012,2015)$ over the Gulf of Mexico: weakening of the Loop Current (Fig. 8) and an intense warming of about $4^{\circ} \mathrm{C}$ in the continental shelf and shelf break especially during summer (Fig. 10). However, increased eddy activity under the RCP8.5 scenario (Fig. 11) is inconsistent with Liu et al. (2012, 2015). As noted in Alexander et al. (2020), the experimental design of Liu et al. $(2012,2015)$ is very different from this study. They used a multi-GCM mean to drive a regional ocean model, and thus retained only the linear component of the climate change forcing. Such difference in experimental design (i.e., climate change forcing) makes it difficult to compare the results side by side. The detailed analysis of Loop Current eddies under the RCP8.5 scenario remains to be assessed in future studies.

\section{Coastal environment projections: Gulf of Maine}

Here we examine the climatic changes within the Gulf of Maine in greater detail, given the strong warming that has already occurred there and is projected to continue into the future (e.g., Saba et al. 2016; see our Figs. 8 and 10). An accurate representation of the present-day coastal circulation is likely to be critical to obtain the three-dimensional structures of changes in the future. As shown in Fig. 1 and Fig. S1 (see also the schematics in Fig. 2), our downscaled present-day simulation captures the essence of the Gulf of Maine circulation, including the topographically trapped Gulf of Maine Coastal Plume (GMCP; Keafer et al. 2005) and Maine Coastal Current (MCC; Anderson et al. 2014). It is also clear that the summertime cyclonic MCC forms in combination with Atlantic water that enters the Gulf of Maine through the Northeast Channel and exits through the Great South and Northeast Channels. The summertime cyclonic MCC is further strengthened in response to RCP8.5 forcings (Fig. 12). The warming is amplified along the sill depth of the Northeast Channel, 
a) Downscaled

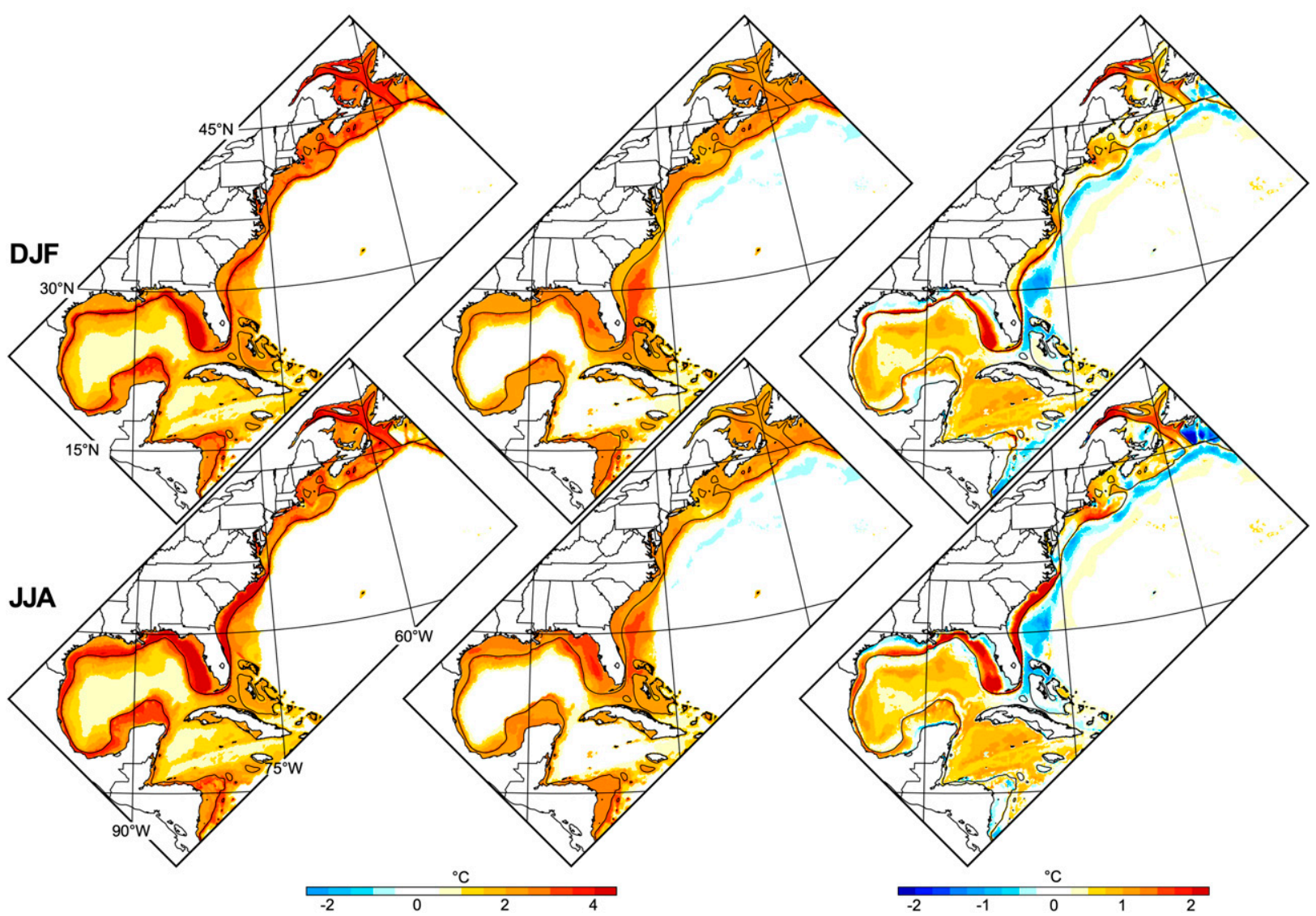

FIG. 10. (top) Maps of projected DJF ocean bottom temperature responses, derived from (a) ROMS downscaling and (b) GFDL ESM2M simulations, and (c) their difference [(a) minus (b)]. For the ease of comparisons, the GFDL ESM2M responses were bilinearly interpolated to the ROMS grid. The gray contours in each map represent the 200-m isobath. (bottom) As in top, but for JJA.

suggesting that a substantial fraction of the warming can be traced to the open ocean.

The open ocean influence on the Gulf of Maine is examined further using a cross section at $42^{\circ} \mathrm{N}$ latitude (Fig. 13), the same cross section as used in Saba et al. (2016). The zonal and vertical velocity changes are shown as vectors, the anomalous northward meridional velocities are dotted, the temperature changes are color shaded, and the salinity differences are contoured. Figure 13 clearly shows the enhanced intrusion of warm and saline open ocean waters into the Gulf of Maine through the channel, resulting in warm saline waters at depth in the gulf. The strengthening of the present-day thermohaline front is also noticeable and may be responsible for the enhanced intrusion of slope waters. These results are qualitatively consistent with the study of Saba et al. (2016), although the magnitudes of changes are much smaller than their estimates.

It is also noteworthy that the sources of those warm and salty slope waters may differ between this study and
Saba et al. (2016). Observations indicate that the Gulf of Maine waters at depth are composed of a mixture of surface and deep waters flowing into the gulf: they are Scotian Shelf Water from the Nova Scotian shelf that enters the Gulf of Maine at the surface and slope waters that enter at depth through the Northeast Channel (e.g., Townsend et al. 2014). There are two distinct types of slope waters: one is Labrador Slope Water and the other is Atlantic Temperate Slope Water (e.g., Bigelow 1927; Ramp et al. 1985; Smith et al. 2001; Townsend et al. 2014; Townsend et al. 2015).

To highlight the source water masses that impact the Gulf of Maine in the CTRL and RCP85 simulations, we estimated the backward trajectory of particles by using TRACMASS (Döös 1995; Döös et al. 2017; http:// tracmass.org) on the output of the currents from both ROMS simulations. We initialized 1521 particles at 5-day intervals from 2 June to 31 August (a total of 28899 particles) over the region $\left(41.63^{\circ}-44.61^{\circ} \mathrm{N} ; 69.90^{\circ}-65.96^{\circ} \mathrm{W}\right.$; thick black box in Fig. 14) between the depths of 145 


\section{a) RCP85}

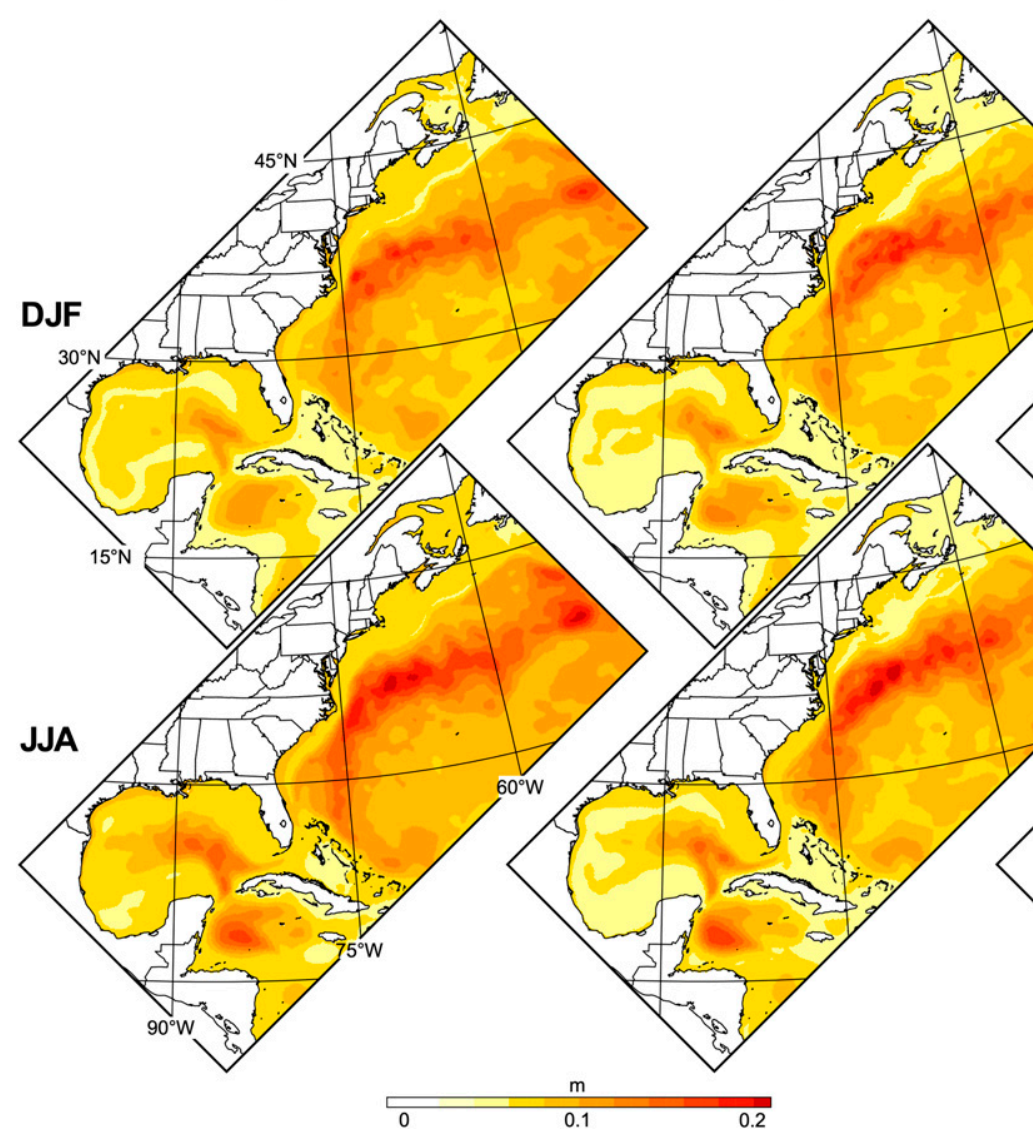

\section{c) RCP85 minus CTRL}

\section{b) CTRL}

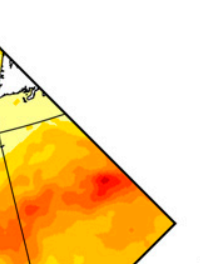

FIG. 11. (top) Maps of DJF high-pass filtered transient ocean eddy statistics derived as sea surface height variance, $\overline{\eta^{\prime 1}}$, in the (a) RCP85 and (b) CTRL simulations, and (c) their differences [(a) minus (b)]. See text for the details of ocean eddy statistics estimation. (bottom) As in top, but for JJA.

and $327 \mathrm{~m}$. These particles were tracked backward by using the mean annual cycle of three-dimensional velocities at a daily time resolution. While the zonal and meridional velocities were obtained from the CTRL and RCP85 runs, the mean annual cycle of vertical velocity was estimated using the continuity equation. Then, the TRACMASS model was integrated backward for 1000 days starting from 31 August.

The water masses that contribute to Gulf of Maine bottom waters in the current climate settings are illustrated in Fig. 14 by randomly choosing 20 particle trajectories. This largely conforms to previous studies on the composition of Gulf of Maine bottom waters, which consist of a mixture of Atlantic Temperate Slope Waters (Gulf Stream), Labrador Subarctic Slope Waters, and Scotian Shelf Waters. There is also substantial recirculation of Gulf Stream waters before they enter the Gulf of Maine.

The maps of instantaneous particle density in the CTRL and RCP85 runs at 200, 500, and 1000 days before the initial time (31 August) are shown in Fig. 15 (see movie clip and Fig. S3 in the online supplemental material for time-varying maps of particle density). We estimated the particle density by counting the number of particles over the whole water column within $1^{\circ} \times 1^{\circ}$ grid boxes. At the first 200-day backward tracking, the Gulf of Maine bottom waters are mostly influenced by the Scotian Shelf Waters. Further back in time $(500$ and 1000 days before the initial time), the Labrador Subarctic Slope Waters and, to a lesser extent, Atlantic Temperate Slope Waters impact the composition of Gulf of Maine bottom waters.

The percentage change of particle densities over time (instantaneous number of particles divided by initial number of particles) over the Gulf of Maine, subtropical North Atlantic $\left(\leq 36^{\circ} \mathrm{N}\right)$, and subpolar North Atlantic $\left(>36^{\circ} \mathrm{N}\right)$ are shown in Fig. 16. During the 1000-day backward integration of TRACMASS, contributions from the subtropical North Atlantic (i.e., Atlantic Temperate Slope Waters) are negligible compared to the subpolar North Atlantic (i.e., Labrador Subarctic Slope Waters). There is substantial recirculation of Gulf Stream Waters 

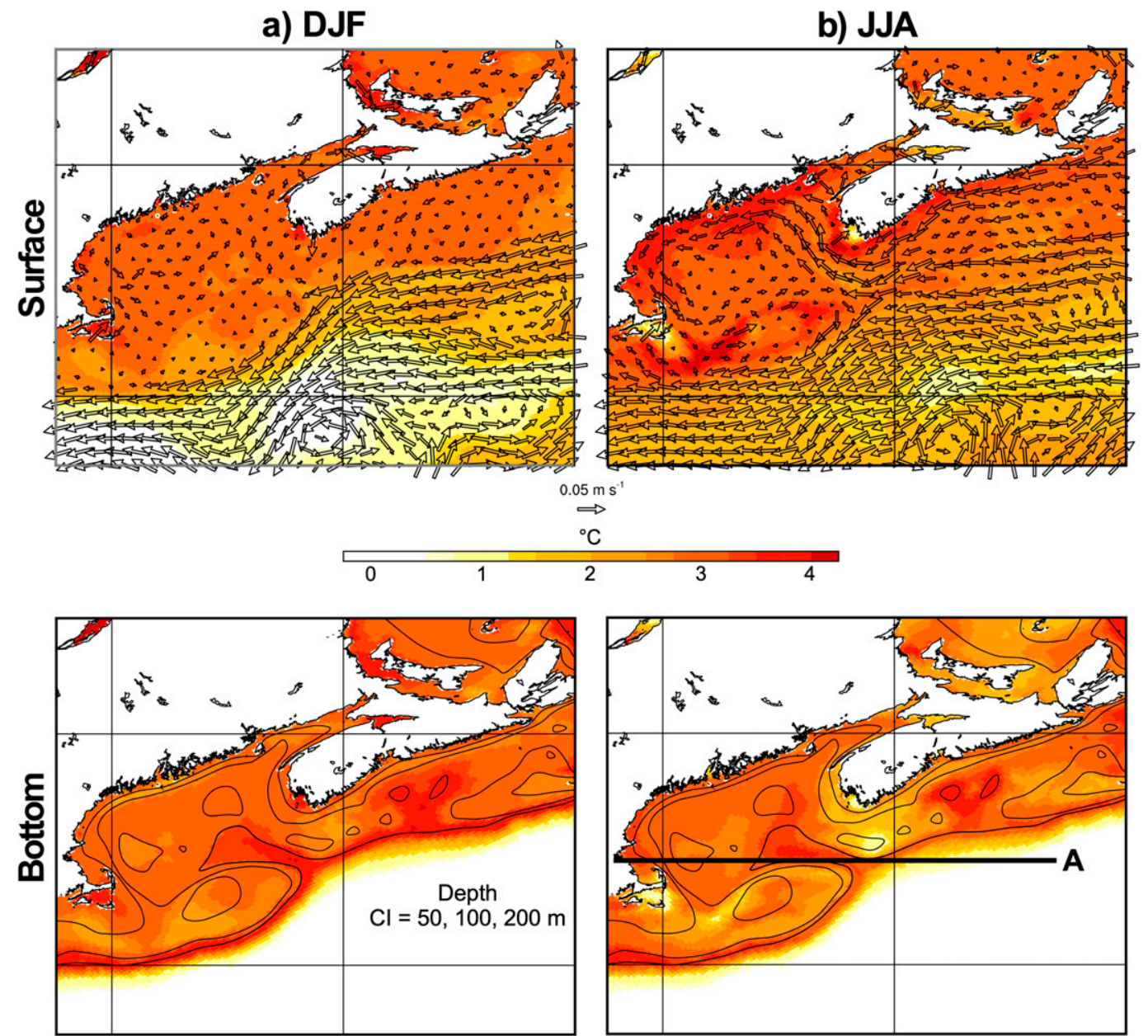

FIG. 12. (top) Maps of projected (a) DJF and (b) JJA temperature (color shadings) and current (vectors) responses at surface derived from ROMS downscaling exercise. (bottom) As in top, but for the responses at ocean bottom. The thick black line $\mathrm{A}$ in the bottom panel represents the zonal cross section $\left(42^{\circ} \mathrm{N}\right.$ latitude) used in Fig. 13.

before entering into the Gulf of Maine (see Fig. 14), and thus the Atlantic Temperate Slope Waters may lose their characteristics by intense mixing before impacting the Gulf of Maine bottom waters.

Figures 15 and 16 indicate that the source waters for the Gulf Maine are very similar in the CTRL and RCP85 runs, including the absence of Gulf Stream waters in the latter. Then why does the Gulf of Maine warm so intensively in the future? The answer may lie in where the temperatures change the most over the North Atlantic, rather than on where the water originated from. In this regard, the intense warming southeast of Newfoundland in response to increased radiative forcing appears in most coupled climate model simulations (e.g., Alexander et al. 2020), including the GFDL-ESM2M. Indeed, the change in temperature between 2070-99 and 1976-2005 exceeds $5^{\circ} \mathrm{C}$ at the surface and $8^{\circ} \mathrm{C}$ at $200-\mathrm{m}$ depth in the vicinity of $46^{\circ} \mathrm{N}, 45^{\circ} \mathrm{W}$ in the GFDL-ESM2M RCP8.5 simulation
(Alexander et al. 2020). The backward particle trajectory results suggest that this very warm water is transported to the Gulf of Maine, and thus the Gulf of Maine warming is predominately forced by changes in the source water properties rather than changes in source water contributions.

\section{Summary and concluding remarks}

In this study, we downscaled the GFDL-ESM2M projected ocean climate changes along the U.S. East and Gulf Coasts using ROMS, an eddy-resolving regional ocean model. The large-scale climate change forcings were obtained from the mean difference (i.e., deltas) between 2070-99 and 1976-2005. We extended previous versions of this method (e.g., Auad et al. 2006; Liu et al. 2012; van Hooidonk et al. 2015) by including a seasonal cycle of the deltas to address the strong 


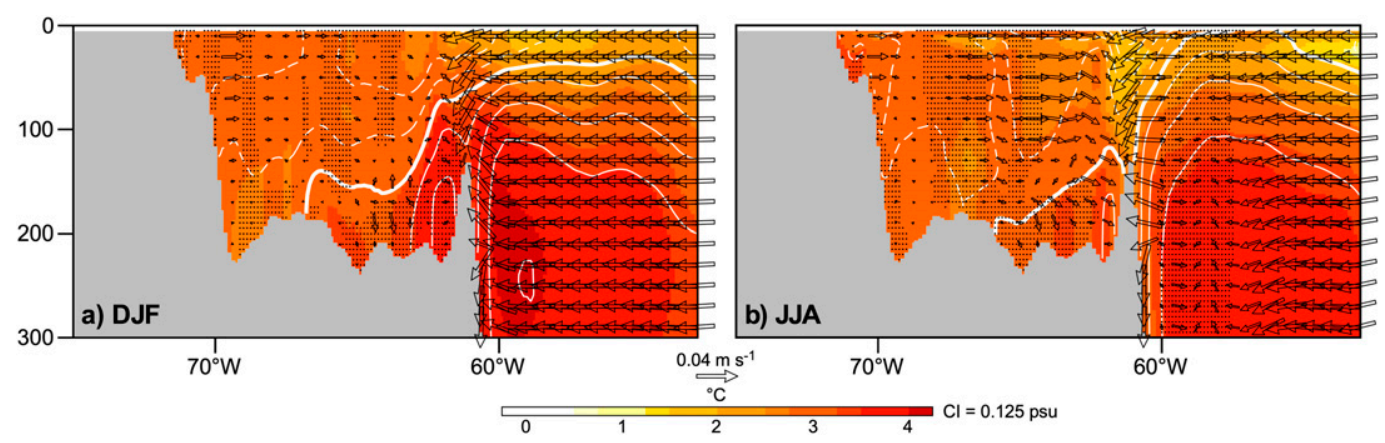

FIG. 13. Zonal cross section of projected (a) DJF and (b) JJA temperature (color shadings), salinity (white contours), and zonal and vertical current (vectors) responses derived from ROMS downscaling runs along the line A (see Fig. 12). The anomalous northward meridional velocities are striped. Negative (zero) salinity changes are denoted as dashed (thick) white contours.

seasonal dependence of climate change (e.g., Partanen et al. 2017). While the delta method removes the mean (present-day) bias and enhances the signal-to-noise ratio of the response, it neglects changes in interannual climate variability. Therefore, our approach can be viewed as a sensitivity test of the response of the coastal ocean to future changes in radiation.

The downscaled climate projection indicates enhanced warming of ocean bottom temperatures relative to the global climate model around the U.S. East and Gulf Coasts, particularly along the continental shelf and shelf break. Enhanced warming also occurs in the Gulf of Maine and Gulf of Saint Lawrence. We attribute the enhanced warming to the improved simulations of coastal ocean hydrography in ROMS. The ROMS control simulation resolved the essence of observed coastal ocean circulation. For example, ROMS captures the topographically trapped GMCP and MCC in the Gulf of Maine and the intrusion of open ocean waters through the Northeast Channel. In response to increasing radiative forcing, the intrusion of slope waters is increased and summertime cyclonic MCC is further strengthened. This leads to enhanced warming in the Gulf of Maine preferentially at depth following the sill depth of Northeast Channel, consistent with Saba et al. (2016).

However, in contrast to Saba et al. (2016), we find that the role of Atlantic Temperate Slope Waters (Gulf Stream Waters) with regard to projected warming at depth in the Gulf of Maine is relatively minor compared to the contribution of Labrador Subarctic Slope Waters. Backward trajectories of particles indicate that Gulf of Maine waters can originate primarily from the subpolar North Atlantic rather than the subtropics. Given the dramatic warming off the coast of Newfoundland and Labrador in climate projections, our results suggest this advective pathway as a key driver for the projected Gulf of Maine warming. Thus, monitoring and modeling of the subpolar North Atlantic are crucial to improve our understanding of changes in the Gulf of Maine.

In closing, some previous studies (e.g., Brooks 1987) suggested the important role of eddies in hydrographic changes over the Gulf of Maine. For example, occasional propagations of Gulf Stream warm core rings into the regions impact Gulf of Maine temperatures at depth by modifying the characteristics of slope waters. Our downscaled projection shows substantial changes in eddies in response to RCP8.5 radiative forcings. However, the detailed dynamical linkage between the Gulf Stream eddies and the hydrographic changes over the Gulf of Maine, and the relative importance of the

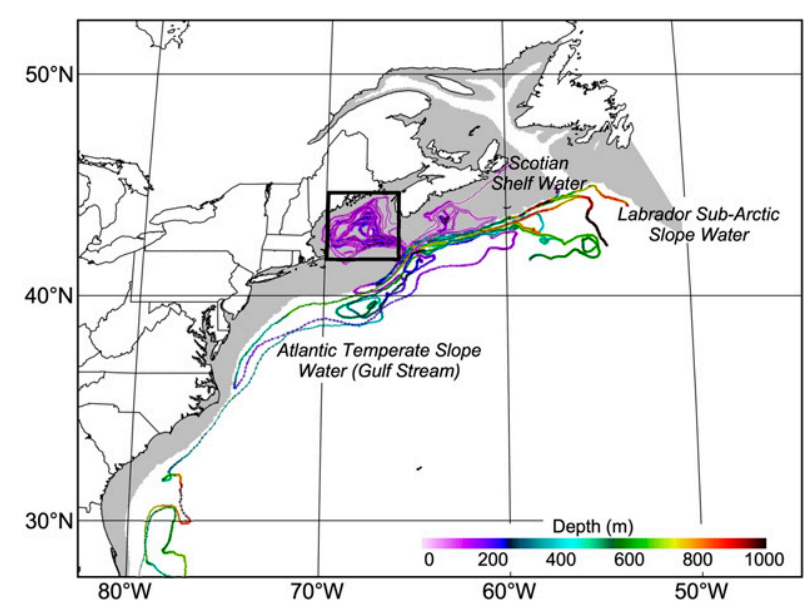

FIG. 14. The initial location map of 28899 particles. The location is denoted as thick black box representing the volumes spanning $41.63^{\circ}-44.61^{\circ} \mathrm{N}, 69.90^{\circ}-65.96^{\circ} \mathrm{W}$, and $145-327 \mathrm{~m}$. The colored lines denote the three-dimensional backward tracking of randomly chosen 20 particles located initially within the box for 1000 days. The gray shadings in each map represent the continental shelves where the water depth is shallower than $200 \mathrm{~m}$. 
a) 200 Days Before

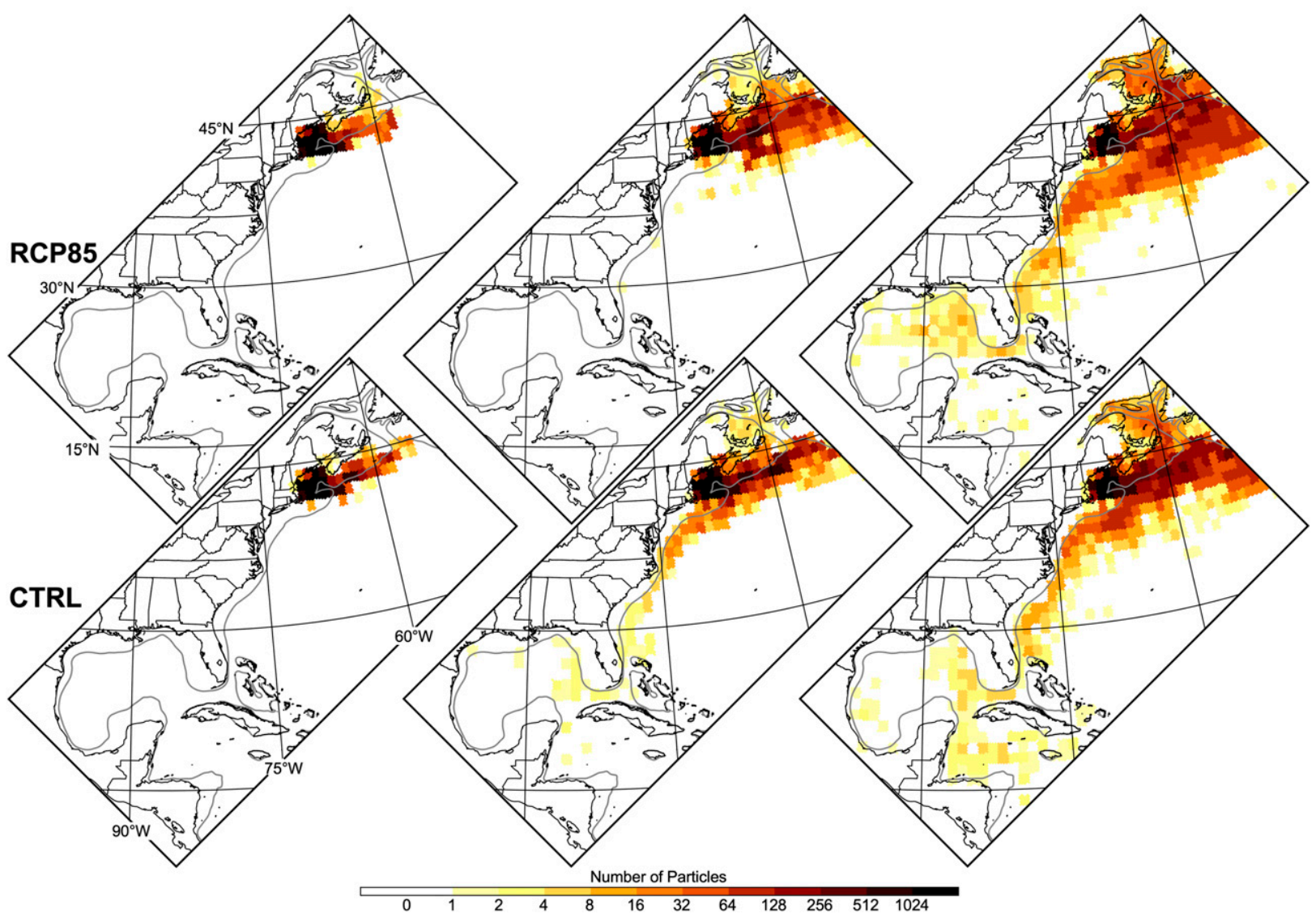

FIG. 15. (top) Maps of particle density at (a) 200, (b) 500, and (c) 1000 days before the initial time (2 Jun) derived from the RCP85 run. (bottom) As in top, but for CTRL. See text for the details of backward particle tracking and particle density estimation. The gray contours in each map represent the $200-\mathrm{m}$ isobath.

eddy impacts on the mean circulation changes, remains to be assessed in future studies.

Acknowledgments. This work was supported by the NOAA/CPO COCA program, Grant NA-15OAR4310133. We thank Drs. Charles Stock and Enrique Curchitser for discussion on the results. We also thank Dr. Michael Jacox for his insightful comments on the manuscript.

\section{APPENDIX}

\section{Path of the Gulf Stream versus Strength of AMOC}

Observational (e.g., Peña-Molino and Joyce 2008) and modeling studies (e.g., de Coëtlogon et al. 2006; Zhang 2008; Kwon and Frankignoul 2014; Yeager 2015) indicate that the path of Gulf Stream and the strength of AMOC are dynamically linked, although the direction of relationship is still in debate. For example, in response to reduced AMOC, some modeling studies (e.g., Zhang 2008; Yeager 2015) suggest a northward shift of the Gulf Stream, while others (e.g., de Coëtlogon et al. 2006; Kwon and Frankignoul 2014) suggest the opposite. Observations appear to support the former (e.g., Peña-Molino and Joyce 2008; Wu et al. 2012), although the limited length of data obscures any statistical significance [see Fig. 8 of Saba et al. (2016)].

Zhang and Vallis (2007) provide a simple dynamical explanation of how the path of Gulf Stream can be tied to the AMOC strength by using a vertically integrated vorticity equation in the presence of ocean topography. For example, in the presence of a linear zonal slope of height $z_{b}$ at its western edge sloping downward to zero at a point in the basin $x_{b}$,

$$
z_{b}(x)=\left\{\begin{array}{ll}
z\left(x_{b}-x\right) & 0 \leq x \leq x_{b} \\
0 & \text { otherwise }
\end{array}, \text { where } z>0,\right.
$$




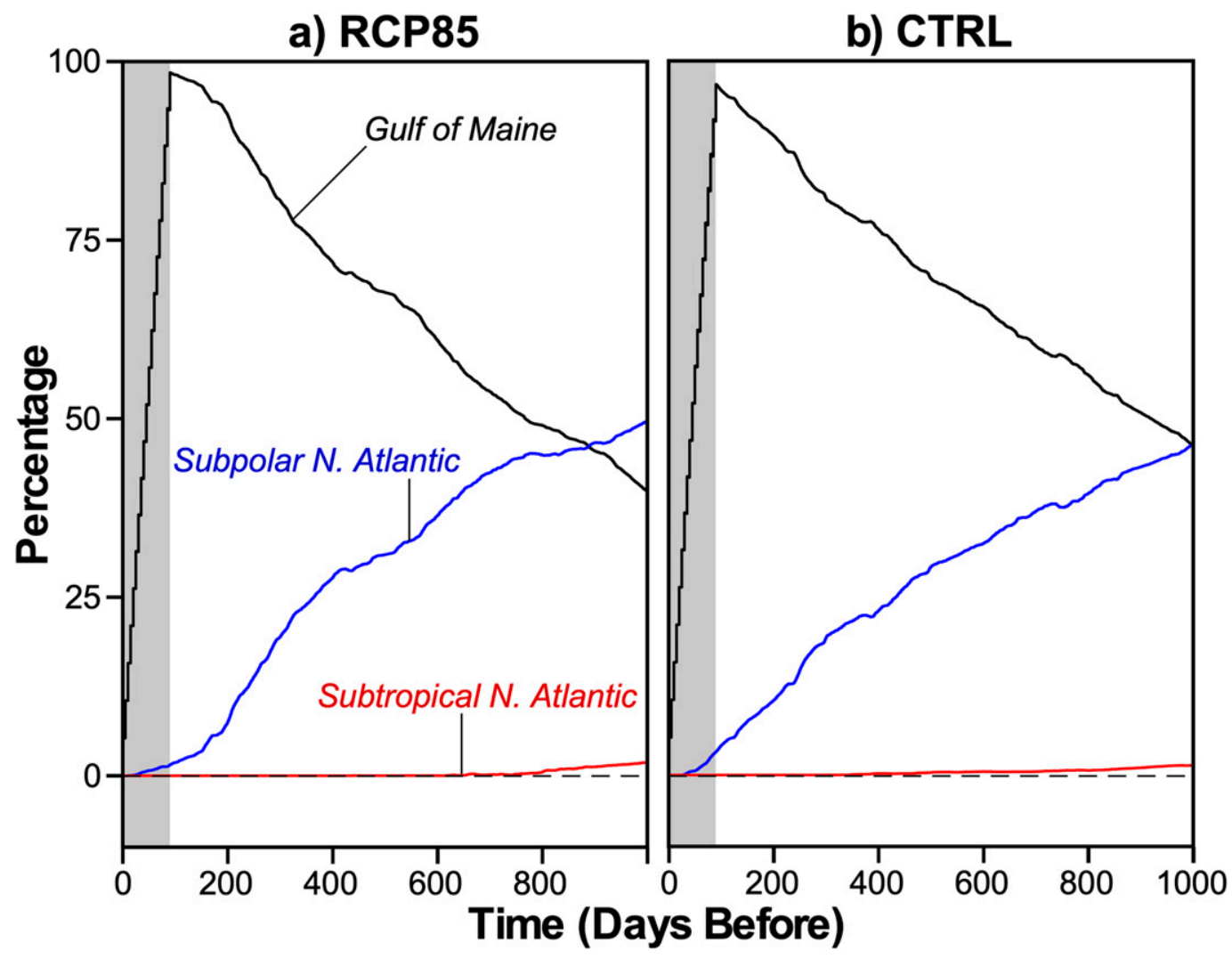

FIG. 16. (a) Percentage changes of particle densities over time, integrated over the Gulf of Maine (black line), subtropical North Atlantic (red line), and subpolar North Atlantic (blue line), derived from the RCP85 run. (b) As in (a) but for CTRL.

the steady barotropic vorticity equation over the inviscid ocean interior can be written as $\beta \partial_{x} \psi_{B}=f_{0}\left(W_{E}-W_{B}\right) / H$, where $H$ is the undisturbed flat ocean depth, the Coriolis parameter $f$ varies linearly with latitude using the $\beta$ plane, $W_{E}$ denotes the surface Ekman pumping, and $W_{B}=$ $J\left(\psi_{B}, z_{b}\right)=\partial_{x} \psi_{B} \partial_{y} z_{b}-\partial_{x} z_{b} \partial_{y} \psi_{B}$ denotes barotropic vortex stretching/compression due to the interaction between ocean circulation and the underlying topography. By integrating the equation from the eastern boundary $(x=L)$, the total interior transport $\psi_{B}$ can be obtained as the sum of (i) the Sverdrup transport $\Psi$ and (ii) the transport induced by bottom vortex stretching $\psi_{W_{B}}$ :

$$
\psi_{B}=\Psi+\psi_{W_{B}}=\underbrace{-\frac{f_{0}}{\beta H} \int_{x}^{L} W_{E} d x}_{\text {(i) }}+\underbrace{\frac{f_{0}}{\beta H} \int_{x}^{L} W_{B} d x}_{\text {(ii) }} .
$$

At the gyre boundary $\left(\psi_{B}=0\right)$ with any observation-like Ekman pumping, $W_{B}<0$, and thus $\psi_{W_{B}}<0$. Therefore the western boundary current tends to separate over the regions where $\Psi>0$ (i.e., south of zero wind stress curl line) due to the bottom vortex stretching to satisfy $\psi_{B}=0$.
Zhang and Vallis (2007) further investigated how variations in AMOC strength could influence the Gulf Stream via changes in bottom vortex stretching. The method they used was to diagnose the bottom vortex stretching term from a primitive equation ocean model, and then prescribe it as a bottom boundary forcing in a barotropic quasigeostrophic (QG) ocean model. Their results suggest that a reduced AMOC induces less bottom vortex stretching resulting in a northward shift of western boundary current; however, by design, the JEBAR (Mertz and Wright 1992) was not interactive in their model.

To incorporate the effects of JEBAR interactively, we used a two-layer eddy-resolving QG model with bottom topography $\left[z_{b}\right.$; see (A1)], the ocean component of the QG Coupled Model (Q-GCM; Hogg et al. 2003). The vertical buoyancy fluxes between the two layers represented as interfacial mass flux $\left(w_{s}\right)$ over an idealized square shape ocean in midlatitude. The domain dimensions are $L \times L$ and the mean layer thicknesses of the upper and lower layers are $\mathrm{H}_{1}$ and $\mathrm{H}_{2}$ respectively. The equation for the evolution of the QG potential vorticity (QGPV) anomaly $(q)$ and the associated 


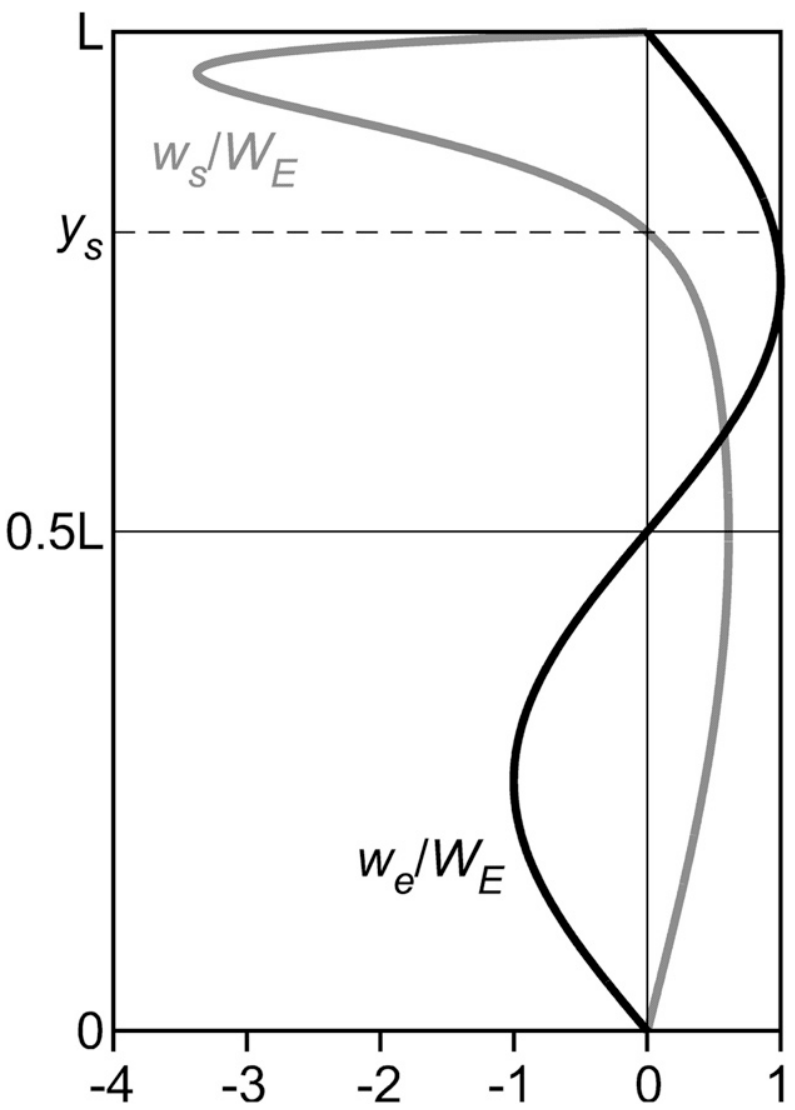

FIG. A1. Black and gray lines represent the meridional distributions of Ekman pumping velocity $w_{e}$ at the midaxis of the basin $(x=0.5 L)$ and buoyancy flux $w_{s}$, respectively. Both $w_{e}$ and $w_{s}$ are normalized by the Ekman pumping velocity $W_{E}$ that yields a maximum interior Sverdrup transport of $30 \mathrm{~Sv}$.

elliptic equation for velocity streamfunction $(\psi)$ in each layer are
TABLE A1. Parameters used in two-layer eddy-resolving QG model.
Basin domain $(L \times L)$

Layer thickness $\left(H_{1}, H_{2}\right)$

Total depth $(H)$

Maximum slope height $(z)$

Zonal extent of slope $\left(x_{b}\right)$

Coriolis parameter $\left(f=f_{0}+\beta y\right)$

Reduced gravity

Biharmonic dissipation coefficient

Bottom friction coefficient

Resolution

Time step
Total sinking mass flux $\left(Q_{0}\right)$
$(4000 \mathrm{~km} \times 4000 \mathrm{~km})$

$(1000 \mathrm{~m}, 3000 \mathrm{~m})$

$4000 \mathrm{~m}$

$1000 \mathrm{~m}$

$1000 \mathrm{~km}$

$\beta=2 \times 10^{-11} \mathrm{~m}^{-1} \mathrm{~s}^{-1}$

$g^{\prime}=g\left(\Delta \rho / \rho_{0}\right)=0.02 \mathrm{~m} \mathrm{~s}^{-2}$

$A_{H}=2 \times 10^{10} \mathrm{~m}^{4} \mathrm{~s}^{-1}$

$\sigma=1 \times 10^{-7} \mathrm{~s}^{-1}$

$10 \mathrm{~km}$

$30 \mathrm{~min}$ $7.5 \mathrm{~Sv}$ $f_{0}=1 \times 10^{-4} \mathrm{~s}^{-1}$

$$
\begin{aligned}
\partial_{t} q_{1}+J\left(\psi_{1}, q_{1}\right) & =\frac{f_{0}}{H_{1}}\left(w_{e}-w_{s}\right)+A_{H} \nabla^{6} \psi_{1} \\
\partial_{t} q_{2}+J\left(\psi_{2}, q_{2}\right) & =\frac{f_{0}}{H_{2}} w_{s}+A_{H} \nabla^{6} \psi_{2}-\sigma \nabla^{2} \psi_{2} \\
q_{1} & =\nabla^{2} \psi_{1}+\beta y+\frac{f_{0}^{2}}{g^{\prime} H_{1}}\left(\psi_{2}-\psi_{1}\right) \\
q_{2} & =\nabla^{2} \psi_{2}+\beta y+\frac{f_{0}^{2}}{g^{\prime} H_{2}}\left(\psi_{1}-\psi_{2}\right)+\frac{f_{0}}{H_{2}} z_{b},
\end{aligned}
$$

where $w_{e}$ is the surface Ekman pumping and $A_{H}$ and $\sigma$ are respectively the biharmonic diffusion and linear bottom friction coefficients. Here, we used the analytic forms of $w_{e}$ (e.g., Karabasov et al. 2009) and $w_{s}$ (e.g., Wu et al. 1999):

$$
\begin{aligned}
& w_{e}(x, y)= \begin{cases}-W_{E} \sin \left(\pi \frac{y}{y_{e}}\right) & 0 \leq y<y_{e} \\
W_{E} \sin \left(\pi \frac{y-y_{e}}{L-y_{e}}\right) & y_{e} \leq y \leq L\end{cases} \\
& w_{s}(y)=\theta\left[1-e^{\frac{\mu}{L}\left(y-y_{s}\right)}\right] \sin \left(\pi \frac{y}{L}\right) \frac{y_{e}}{L}=0.5+0.2\left(\frac{x}{L}-0.5\right),
\end{aligned}
$$

where $W_{E}$ is the amplitude of Ekman pumping scaled to yield an observed interior Sverdrup transport of $30 \mathrm{~Sv}$ [i.e. $\left.\Psi=f_{0} W_{E} L /(\beta H)\right]$ in the North Atlantic. The parameter $y_{e}$ controls the asymmetry of $w_{e}$ relative to the midaxis of the basin $(y=0.5 \mathrm{~L})$ and is designed to avoid artificial gyre symmetry. The parameter $y_{s}$ separates a narrow intense sinking at high latitudes from a broad upwelling elsewhere as conceptualized by Stommel et al.
(1958). With predetermined $y_{s}$ and the total sinking mass flux $Q_{0}$ (the same as total upwelling flux to satisfy mass conservation; $Q_{0}=\varepsilon \Psi L \int_{y_{s}}^{L}\left|w_{s}\right| d y=\varepsilon \Psi L \int_{0}^{y_{s}} w_{s} d y$, where $\varepsilon=\beta L / f_{0}$ ), unique $\mu$ and $\theta$ are determined. The meridional distributions of $w_{e}$ and $w_{s}$ are shown in Fig. A1, and the standard values of parameters used are summarized in Table A1. Free-slip conditions are applied to all lateral boundaries. All numerical experiments were 


\section{$Q / Q_{0}-1-0.75-0.5-0.25-0 \rightarrow$}

\section{a) Stommel-Type Broad Upwelling}
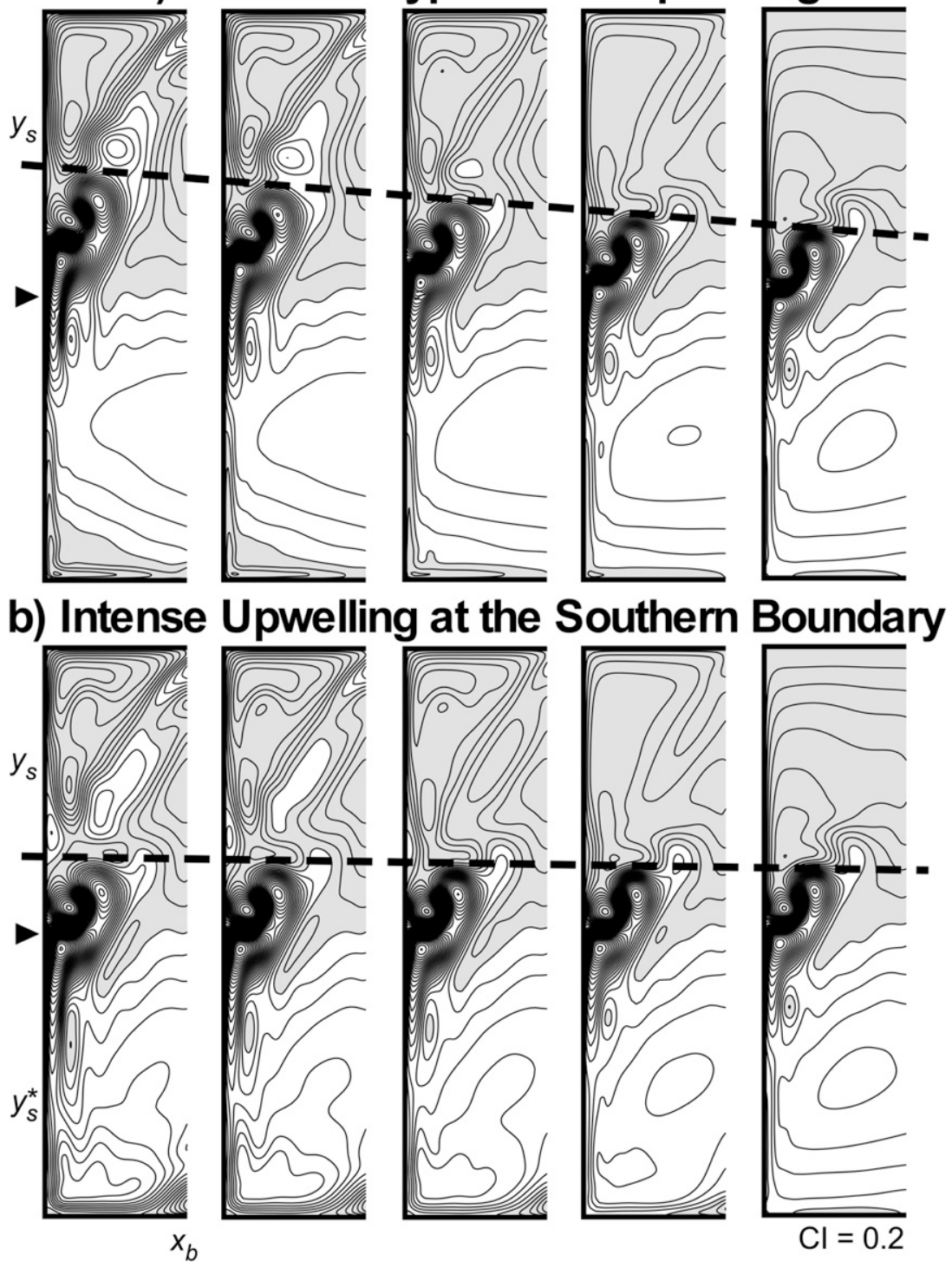

FIG. A2. The wind and buoyancy-driven barotropic streamfunction over the slope as the function of AMOC strength $\left(Q ; Q_{0}=7.5 \mathrm{~Sv}\right)$ for the case of (a) Stommel-type broad upwelling $\left(0 \leq y \leq y_{s}\right)$ and (b) intense upwelling at the southern boundary $\left(0 \leq y \leq y_{s}^{*}\right)$. Thick black dashed lines in (a) and (b) denote the meridional extent of western boundary current and its extension over the slope. The contour interval is 0.2 , normalized by the maximum interior Sverdrup transport. The negative values are shaded gray. The black triangles indicate the boundary current separation point at the western boundary for the case of purely wind-driven in the absence of slope.

integrated for 200 years, and the last 100 years were used to estimate time-averaged flow patterns.

A set of QG model experiments was performed by reducing the magnitude of total sinking mass flux $Q$ from $Q_{0}(=7.5 \mathrm{~Sv})$ to $0 \mathrm{~Sv}$, while keeping its meridional profile. The resulting barotropic flow patterns over the slope are shown in Fig. A2a. It clearly indicates that the path of western boundary current shifts southward as AMOC weakens, consistent with our downscaled results and the previous modeling studies (de Coëtlogon et al. 2006; Kwon and Frankignoul 2014).

Could the result shown in Fig. A2a be an artifact of the prescribed profiles of $w_{e}$ and $w_{s}$ ? Mathematically, $w_{s}$ for the upper layer acts like $w_{e}$ [see the term $\sim\left(w_{e}-w_{s}\right)$ 
in the first equation of (A3)], and the net impact of decreased $w_{s}$ (i.e., weakened AMOC) is the same as shifting zero wind stress curl line southward. Thus, the conceptual model for deep-ocean circulation based upon Stommel et al. (1958) connotes the relationship of increased bottom vortex stretching due to weakened AMOC by design. To address this issue, we performed another set of QG model experiments. In this case, the narrow intense sinking at high latitudes from $y_{s}$ to $L$ is balanced by narrow intense upwelling of equal area at the regions of southern boundary spanning the equal area from 0 to $y_{s}^{*}(=0.2 \mathrm{~L})$ to maintain the position of zero wind stress curl line during the experiments.

The results shown in Fig. A2b are qualitatively similar to those in Fig. A2a, although the southward shift of western boundary current is not as dramatic. However, note that the typical western boundary current shift in coupled climate models, if present, is only few degrees in latitude even in the case of $\mathrm{CO}_{2}$ doubling. That is only about $5 \%\left(1^{\circ}-2^{\circ}\right.$ in latitude) of the meridional extent of the subtropical gyre (about $30^{\circ}$ in latitude) (Saba et al. 2016). Moreover, Fig. A2b shows the weakening of subtropical gyre as the AMOC decreases. That is consistent with our downscaled simulations. Although simulating the detailed structure of the deep-ocean circulation is clearly beyond the scope of this study, the general findings appear robust; that is, the path of western boundary current shifts southward as the AMOC weakens.

\section{REFERENCES}

Alexander, M., S.-I. Shin, J. D. Scott, E. Curchitser, and C. Stock, 2020 The response of the northwest Atlantic Ocean to climate change. J. Climate, 33, 405-428, https://doi.org/10.1175/JCLI-D-19-0117.1.

Anderson, D. M., and Coauthors, 2014: Understanding interannual, decadal level variability in paralytic shellfish poisoning toxicity in the Gulf of Maine: The HAB index. Deep-Sea Res. II, 103, 264-276, https://doi.org/10.1016/j.dsr2.2013.09.018.

Anderson, J. L., and Coauthors, 2004: The new GFDL global atmosphere and land model AM2-LM2: Evaluation with prescribed SST simulations. J. Climate, 17, 4641-4673, https:// doi.org/10.1175/JCLI-3223.1.

Andres, M., 2016: On the recent destabilization of the Gulf Stream path downstream of Cape Hatteras. Geophys. Res. Lett., $\mathbf{4 3}$ 9836-9842, https://doi.org/10.1002/2016GL069966.

Auad, G., A. Miller, and E. Di Lorenzo, 2006: Long-term forecast of oceanic conditions off California and their biological implications. J. Geophys. Res., 111, C09008, https://doi.org/ 10.1029/2005JC003219.

Bigelow, H. B., 1927: Physical oceanography of the Gulf of Maine. Bull. U.S. Bur. Fish., 40, 511-1027.

Bonjean, F., and G. S. E. Lagerloef, 2002: Diagnostic model and analysis of the surface currents in the tropical Pacific Ocean. J. Phys. Oceanogr., 32, 2938-2954, https://doi.org/10.1175/ 1520-0485(2002)032<2938:DMAAOT >2.0.CO;2.

Brooks, D. A., 1987: The influence of warm-core rings on the slope water entering the Gulf of Maine. J. Geophys. Res., 92, 81838196, https://doi.org/10.1029/JC092iC08p08183.
Buckley, M., and J. Marshall, 2016: Observations, inferences, and mechanisms of the Atlantic meridional overturning circulation: A review. Rev. Geophys., 54, 5-63, https://doi.org/10.1002/ 2015RG000493.

Caesar, L., S. Rahmstorf, A. Robinson, G. Feulner, and V. Saba, 2018: Observed fingerprint of a weakening Atlantic Ocean overturning circulation. Nature, 556, 191-196, https://doi.org/ 10.1038/s41586-018-0006-5.

Carton, J. A., and B. S. Giese, 2008: A reanalysis of ocean climate using Simple Ocean Data Assimilation (SODA). Mon. Wea. Rev., 136, 2999-3017, https://doi.org/10.1175/2007MWR1978.1.

Chang, Y.-L., and L.-Y. Oey, 2012: Why does the Loop Current tend to shed more eddies in summer and winter? Geophys. Res. Lett., 39, L05605, https://doi.org/10.1029/2011GL050773.

Cheng, W., J. C. H. Chiang, and D. Zhang, 2013: Atlantic meridional overturning circulation (AMOC) in CMIP5 models: RCP and historical simulations. J. Climate, 26, 7187-7197, https:// doi.org/10.1175/JCLI-D-12-00496.1.

Curchitser, E. N., D. B. Haidvogel, A. J. Hermann, E. Dobbins, T. M. Powell, and A. Kaplan, 2005: Multi-scale modeling of the North Pacific Ocean: Assessment of simulated basin-scale variability (1996-2003). J. Geophys. Res., 110, C11021, https:// doi.org/10.1029/2005JC002902.

Dai, A., T. Qian, K. E. Trenberth, and J. D. Milliman, 2009: Changes in continental freshwater discharge from 1948 to 2004. J. Climate, 22, 2773-2792, https://doi.org/10.1175/2008JCLI2592.1.

de Coëtlogon, G., C. Frankignoul, M. Bentsen, C. Delon, H. Haak, S. Masina, and A. Pardaens, 2006: Gulf Stream variability in five ocean general circulation models. J. Phys. Oceanogr., 36, 2119-2135, https://doi.org/10.1175/JPO2963.1.

Döös, K., 1995: Inter-ocean exchange of water masses. J. Geophys. Res., 100, 13 499-13 514, https://doi.org/10.1029/95JC00337.

, B. Jönsson, and J. Kjellsson, 2017: Evaluation of oceanic and atmospheric trajectory schemes in the TRACMASS trajectory model v6.0. Geosci. Model Dev., 10, 1733-1749, https://doi.org/ 10.5194/gmd-10-1733-2017.

Dunne, J. P., and Coauthors, 2012: GFDL's ESM2 global coupled climate-carbon Earth system models. Part I: Physical formulation and baseline simulation characteristics. J. Climate, 25, 6646-6665, https://doi.org/10.1175/JCLI-D-11-00560.1.

Feng, S., and Q. Fu, 2013: Expansion of global drylands under a warming climate. Atmos. Chem. Phys., 13, $10081-10094$, https://doi.org/10.5194/acp-13-10081-2013.

Griffies, S. M., and Coauthors, 2005: Formulation of an ocean model for global climate simulations. Ocean Sci., 1, 45-79, https://doi.org/10.5194/os-1-45-2005.

— , and Coauthors, 2015: Impacts on ocean heat from transient mesoscale eddies in a hierarchy of climate models. J. Climate, 28, 952-977, https://doi.org/10.1175/JCLI-D-14-00353.1.

He, J., and B. J. Soden, 2016: The impact of SST biases on projections of anthropogenic climate change: A greater role for atmosphere-only models? Geophys. Res. Lett., 43, 7745-7750, https://doi.org/10.1002/2016GL069803.

Hoegh-Guldberg, O., and J. F. Bruno, 2010: The impact of climate change on the world's marine ecosystems. Science, 328, 15231528, https://doi.org/10.1126/science.1189930.

Hogg, A. M., J. R. Blundell, W. K. Dewar, and P. D. Killworth, 2003: Formulation and users' guide for Q-GCM (version 1.0). Southampton Oceanography Centre, Internal Doc. 88, 40 pp., http://www.q-gcm.org/downloads/q-gcmv1.0.pdf.

IPCC, 2013: Climate Change 2013: The Physical Science Basis. Cambridge University Press, 1535 pp., https://doi.org/10.1017/ CBO9781107415324. 
Jouanno, J., J. Sheinbaum, B. Barnier, J.-M. Molines, L. Debreu, and F. Lemarié, 2008: The mesoscale variability in the Caribbean Sea. Part I: Simulations and characteristics with an embedded model. Ocean Modell., 23, 82-101, https://doi.org/ 10.1016/j.ocemod.2008.04.002.

Kang, D., and E. N. Curchitser, 2013: Gulf Stream eddy characteristics in a high-resolution ocean model. J. Geophys. Res. Oceans., 118, 4474-4487, https://doi.org/10.1002/jgrc.20318.

$\longrightarrow$, and _ 2015: Energetics of eddy-mean flow interactions in the Gulf Stream region. J. Phys. Oceanogr., 45, 1103-1120, https://doi.org/10.1175/JPO-D-14-0200.1.

Karabasov, S. A., P. S. Berloff, and V. M. Goloviznin, 2009: CABARET in the ocean gyres. Ocean Modell., 30, 155-168, https://doi.org/10.1016/j.ocemod.2009.06.009.

Keafer, B. A., J. H. Churchill, D. J. McGillicuddy Jr., and D. M. Anderson, 2005: Bloom development and transport of toxic Alexandrium fundyense populations within a coastal plume in the Gulf of Maine. Deep-Sea Res. II, 52, 2674-2697, https:// doi.org/10.1016/j.dsr2.2005.06.016.

Kwon, Y.-O., and C. Frankignoul, 2014: Mechanisms of multidecadal Atlantic meridional overturning circulation variability diagnosed in depth versus density space. J. Climate, 27, 9359-9376, https://doi.org/10.1175/JCLI-D-14-00228.1.

Large, W. G., and S. G. Yeager, 2009: The global climatology of an interannually varying air-sea flux data set. Climate Dyn., 33, 341-364, https://doi.org/10.1007/s00382-008-0441-3.

Le Bris, A., and Coauthors, 2018: Climate vulnerability and resilience in the most valuable North American fishery. Proc. Natl. Acad. Sci. USA, 115, 1831-1836, https://doi.org/10.1073/pnas.1711122115.

Liu, Y., S.-K. Lee, B. A. Muhling, J. T. Lamkin, and D. B. Enfield, 2012: Significant reduction of the Loop Current in the 21st century and its impact on the Gulf of Mexico. J. Geophys. Res., 117, C05039, https://doi.org/10.1029/2011JC007555.

,,-- D. B. Enfield, B. A. Muhling, J. T. Lamkin, F. MullerKarger, and M. A. Roffer, 2015: Potential impact of climate change on the Intra-Americas Seas: Part-1. A dynamic downscaling of the CMIP5 model projections. J. Mar. Syst., 148, 56-69, https://doi.org/10.1016/j.jmarsys.2015.01.007.

Lu, J., G. A. Vecchi, and T. Reichler, 2007: Expansion of the Hadley cell under global warming. Geophys. Res. Lett., 34, L06805, https://doi.org/10.1029/2006GL028443.

Lumpkin, R., and G. C. Johnson, 2013: Global ocean surface velocities from drifters: Mean, variance, El Niño-Southern Oscillation response, and seasonal cycle. J. Geophys. Res. Oceans, 118, 2992-3006, https://doi.org/10.1002/jgrc.20210.

Mertz, G., and G. D. Wright, 1992: Interpretation of the JEBAR term. J. Phys. Oceanogr., 22, 301-305, https://doi.org/10.1175/ 1520-0485(1992)022<0301:IOTJT>2.0.CO;2.

Minobe, S., M. Terada, B. Qiu, and N. Schneider, 2017: Western boundary sea level: A theory, rule of thumb, and application to climate models. J. Phys. Oceanogr., 47, 957-977, https:// doi.org/10.1175/JPO-D-16-0144.1.

Munk, W. H., 1950: On the wind-driven ocean circulation. J. Meteor., 7, 79-93, https://doi.org/10.1175/1520-0469(1950) 007<0080:OTWDOC $>2.0$.CO;2.

Partanen, A.-I., M. Leduc, and H. D. Matthews, 2017: Seasonal climate change patterns due to cumulative $\mathrm{CO}_{2}$ emissions. Environ. Res. Lett., 12, 075002, https://doi.org/10.1088/1748-9326/aa6eb0.

Peña-Molino, B., and T. M. Joyce, 2008: Variability in the slope water and its relation to Gulf Stream path. Geophys. Res. Lett., 35, L03606, https://doi.org/10.1029/2007GL032183.

Pershing, A. J., and Coauthors, 2015: Slow adaptation in the face of rapid warming leads to collapse of the Gulf of Maine cod fishery. Science, 350, 809-812, https://doi.org/10.1126/ science.aac9819.

Ramp, S. R., R. J. Schlitz, and W. R. Wright, 1985: The deep flows through the Northeast Channel, Gulf of Maine. J. Phys. Oceanogr., 15, 1790-1808, https://doi.org/10.1175/ 1520-0485(1985)015<1790:TDFTTN>2.0.CO;2.

Saba, V. S., and Coauthors, 2016: Enhanced warming of the northwest Atlantic Ocean under climate change. J. Geophys. Res. Oceans, 121, 118-132, https://doi.org/10.1002/2015JC011346.

Shchepetkin, A. F., and J. C. McWilliams, 2005: The Regional Oceanic Modeling System (ROMS): A split-explicit, freesurface, topography-following-coordinate oceanic model. Ocean Modell., 9, 347-404, https://doi.org/10.1016/j.ocemod.2004.08.002.

Small, R. J., and Coauthors, 2014: A new synoptic scale resolving global climate simulation using the Community Earth System Model. J. Adv. Model. Earth Syst., 6, 1065-1094, https:// doi.org/10.1002/2014MS000363.

Smith, P. C., W. W. Houghton, R. G. Fairbanks, and D. G. Mountain, 2001: Interannual variability of boundary fluxes and water mass properties in the Gulf of Maine and on Georges Bank: 1993-1997. Deep-Sea Res. II, 48, 37-70, https:// doi.org/10.1016/S0967-0645(00)00081-3.

Stommel, H., A. B. Arons, and A. J. Faller, 1958: Some examples of stationary flow patterns in bounded basins. Tellus, 10,179-187, https://doi.org/10.3402/tellusa.v10i2.9238.

Taylor, K. E., R. J. Stouffer, and G. A. Meehl, 2012: An overview of CMIP5 and the experiment design. Bull. Amer. Meteor. Soc., 93, 485-498, https://doi.org/10.1175/BAMS-D-11-00094.1.

Townsend, D. W., D. J. McGillicuddy Jr., M. A. Thomas, and N. D. Rebuck, 2014: Nutrients and water masses in the Gulf of Maine-Georges Bank region: Variability and importance to blooms of the toxic dinoflagellate Alexandrium fundyense. Deep-Sea Res. II, 103, 238-263, https://doi.org/10.1016/ j.dsr2.2013.08.003.

_, N. R Pettigrew, M. A. Thomas, M. G. Neary, D. J. McGillicuddy Jr., and J. O'Donnell, 2015: Water masses and nutrient sources to the Gulf of Maine. J. Mar. Res., 73, 93-122, https://doi.org/10.1357/002224015815848811.

van Hooidonk, R., J. A. Maynard, Y. Liu, and S.-K. Lee, 2015: Downscaled projections of Caribbean coral bleaching that can inform conservation planning. Global Change Biol., 21, 33893401, https://doi.org/10.1111/gcb.12901.

Wu, L., Z. Liu, and H. E. Hurlburt, 1999: The effect of continental slope on buoyancy-driven circulation. J. Phys. Oceanogr., 29, 1881-1891, https://doi.org/10.1175/1520-0485(1999)029<1881: TEOCSO $>2.0 . \mathrm{CO} ; 2$.

— subtropical western boundary currents. Nat. Climate Change, 2, 161-166, https://doi.org/10.1038/nclimate1353.

Yeager, S., 2015: Topographic coupling of the Atlantic overturning and gyre circulations. J. Phys. Oceanogr., 45, 1258-1284, https://doi.org/10.1175/JPO-D-14-0100.1.

Zhai, X., R. J. Greatbatch, and J.-D. Kohlmann, 2008: On the seasonal variability of eddy kinetic energy in the Gulf Stream region. Geophys. Res. Lett., 35, L24609, https://doi.org/10.1029/ 2008 GL036412.

Zhang, R., 2008: Coherent surface-subsurface fingerprint of the Atlantic meridional overturning circulation. Geophys. Res. Lett., 35, L20705, https://doi.org/10.1029/2008GL035463.

_ - and G. K. Vallis, 2007: The role of bottom vortex stretching on the path of the North Atlantic western boundary current and on the northern recirculation gyre. J. Phys. Oceanogr., 37, 2053-2080, https://doi.org/10.1175/JPO3102.1. 